\title{
Statin intolerance - an attempt at a unified definition. Position paper from an International Lipid Expert Panel
}

Maciej Banach ${ }^{1}$, Manfredi Rizzo ${ }^{2}$, Peter P. Toth ${ }^{3}$, Michel Farnier ${ }^{4}$, Michael H. Davidson ${ }^{5}$, Khalid Al-Rasadi ${ }^{6}$, Wilbert S. Aronow ${ }^{7}$, Vasilis Athyros ${ }^{8}$, Dragan M. Djuric ${ }^{9}$, Marat V. Ezhov ${ }^{10}$, Robert S. Greenfield ${ }^{11}$, G. Kees Hovingh ${ }^{12}$, Karam Kostner ${ }^{13}$, Corina Serban ${ }^{14}$, Daniel Lighezan ${ }^{14}$, Zlatko Fras ${ }^{15}$, Patrick M. Moriarty ${ }^{16}$, Paul Muntner ${ }^{17}$, Assen Goudev ${ }^{18}$, Richard Ceska ${ }^{19}$, Stephen J. Nicholls ${ }^{20}$, Marlena Broncel ${ }^{21}$, Dragana Nikolic ${ }^{2}$, Daniel Pella ${ }^{22}$, Raman Puri' ${ }^{23}$, Jacek Rysz ${ }^{1}$, Nathan D. Wong ${ }^{24}$, Laszlo Bajnok ${ }^{25}$, Steven R. Jones ${ }^{26}$, Kausik K. Ray²7, Dimitri P. Mikhailidis ${ }^{28}$

${ }^{1}$ Department of Hypertension, Chair of Nephrology and Hypertension, Medical University of Lodz, Lodz, Poland

${ }^{2}$ Biomedical Department of Internal Medicine and Medical Specialties, University of Palermo, Palermo, Italy

${ }^{3}$ University of Illinois College of Medicine, Peoria, IL, USA

${ }^{4}$ Department of Lipidology, Point Medical, Dijon, France

${ }^{5}$ Department of Medicine, University of Chicago Medicine, Chicago, IL, USA

${ }^{6}$ Department of Clinical Biochemistry, SQUH, Muscat, Oman

${ }^{7}$ Cardiology Division, Department of Medicine, Westchester Medical Center/New York Medical College, Valhalla, New York, USA

${ }^{8}$ Second Propedeutic Department of Internal Medicine, Medical School, Aristotle University of Thessaloniki, Hippocration Hospital, Thessaloniki, Greece ${ }^{9}$ Institute of Medical Physiology, Faculty of Medicine, University of Belgrade, Belgrade, Serbia

${ }^{10}$ Department of Atherosclerosis, Cardiology Research Center, Moscow, Russia

${ }^{11}$ California Heart Associates, CA, USA

${ }^{12}$ Department of Vascular Medicine, Academic Medical Center,

University of Amsterdam, Amsterdam, The Netherlands

${ }^{13}$ Mater Hospital, University of Queensland, St Lucia, QLD, Australia

${ }^{14}$ University of Medicine and Pharmacy "Victor Babes" Timisoara, Romania

${ }^{15}$ Department of Vascular Medicine, Preventive Cardiology Unit, University Medical Centre Ljubljana, Slovenia Internal Medicine, Faculty of Medicine,

University of Ljubljana, Ljubljana, Slovenia

${ }^{16}$ Department of Medicine, Schools of Pharmacy and Medicine,

The University of Kansas Medical Center, Kansas City, KS, USA

${ }^{17}$ Department of Epidemiology, University of Alabama at Birmingham, Birmingham, AL, USA

${ }^{18}$ Department of Cardiology, Queen Giovanna University Hospital, Sofia, Bulgaria

${ }^{19} 3^{\text {rd }}$ Department of Internal Medicine, Charles University, Praha, Czech Republic

${ }^{20}$ South Australian Health and Medical Research Institute and University of Adelaide, Adelaide, Australia

${ }^{21}$ Department of Internal Medicine and Clinical Pharmacology, Medical University of Lodz, Poland

${ }^{22}$ First Department Of Internal Medicine, Pavol Jozef Safarik University and Louis Pasteur University Hospital, Košice, Slovakia

23। P Apollo Hospital, New Delhi, India

${ }^{24} \mathrm{Heart}$ Disease Prevention Program, Division of Cardiology, University of California, Irvine, Irvine, CA, USA

${ }^{25}$ First Department of Medicine, University of Pecs, Pecs, Hungary

${ }^{26}$ The Johns Hopkins Ciccarone Center for the Prevention of Heart Disease, Baltimore, MD, USA

${ }^{27}$ Department of Primary Care and Public Health, School of Public Health, Imperial College London, London, UK

${ }^{28}$ Department of Clinical Biochemistry, Royal Free Campus, University College London Medical School, University College London (UCL), London, UK

\author{
Corresponding author: \\ Prof. Maciej Banach MD, PhD, \\ FNLA, FAHA, FESC, FASA, FRSPH \\ Department of Hypertension \\ Chair of Nephrology and \\ Hypertension \\ Medical University of Lodz \\ 113 Zeromskiego St \\ 90-549 Lodz, Poland \\ Phone: +48 426393771 \\ Fax: +48 426393771 \\ E-mail: \\ maciejbanach@aol.co.uk
}

Submitted: 5 March 2015

Accepted: 10 March 2015

Arch Med Sci 2015; 11, 1: 1-23

DOI: 10.5114/aoms.2015.49807

Copyright @ 2015 Termedia \& Banach 
M. Banach, M. Rizzo, P.P. Toth, M. Farnier, M.H. Davidson, K. Al-Rasadi, W.S. Aronow, V. Athyros, D.M. Djuric, M.V. Ezhov, R.S. Greenfield, G.K. Hovingh, K. Kostner, C. Serban, D. Lighezan, Z. Fras, P.M. Moriarty, P. Muntner, A. Goudev, R. Ceska, S.J. Nicholls, M. Broncel, D. Nikolic, D. Pella, R. Puri, J. Rysz, N.D. Wong, L. Bajnok, S.R. Jones, K.K. Ray, D.P. Mikhailidis

\begin{abstract}
Statins are one of the most commonly prescribed drugs in clinical practice. They are usually well tolerated and effectively prevent cardiovascular events. Most adverse effects associated with statin therapy are musclerelated. The recent statement of the European Atherosclerosis Society (EAS) has focused on statin associated muscle symptoms (SAMS), and avoided the use of the term 'statin intolerance'. Although muscle syndromes are the most common adverse effects observed after statin therapy, excluding other side effects might underestimate the number of patients with statin intolerance, which might be observed in $10-15 \%$ of patients. In clinical practice, statin intolerance limits effective treatment of patients at risk of, or with, cardiovascular disease. Knowledge of the most common adverse effects of statin therapy that might cause statin intolerance and the clear definition of this phenomenon is crucial to effectively treat patients with lipid disorders. Therefore, the aim of this position paper was to suggest a unified definition of statin intolerance, and to complement the recent EAS statement on SAMS, where the pathophysiology, diagnosis and the management were comprehensively presented.
\end{abstract}

Key words: definition, muscle symptoms, risk factors, statin intolerance.

\section{Introduction}

Statins are commonly prescribed in clinical practice [1]. They are well tolerated and effectively prevent cardiovascular (CV) events [1-3]. However, some controversy remains regarding the clinical benefits of statins in primary prevention patients with low and moderate CV risk (e.g. $\mathrm{CV}$ benefit and risk of new onset diabetes (NOD)) [4] as well as high-risk patients (e.g. relatively low use of high doses of statins) [1]. Taking the latter into account, the current American College of Cardiology (ACC)/American Heart Association (AHA) guidelines support widespread statin use and more intensive statin therapy [1]. The new Pooled Cohort Risk calculator may result in a larger population qualifying for statin therapy (combination therapy is practically not mentioned); this has been a matter of debate $[5,6]$. If more patients start statin therapy because of overestimated risk this might be a reason for more cases of statin non-adherence due to treatment-related side effects [7].

Most adverse effects (AEs) associated with statin therapy are muscle-related. We can find definitions like: statin-associated myalgia/myopathy, statin-induced myalgia/myopathy or statin-related myalgia/myopathy (or muscle symptoms (SAMS)) [7-9]. The most recent statement of the European Atherosclerosis Society (EAS) has focused on SAMS, and avoided the use of the term 'statin intolerance', as it is not specific for muscle symptoms [10]. Although muscle syndromes are the most common adverse effects observed after statin therapy, excluding other side effects might underestimate the number of patients with true statin intolerance [7]
Statin intolerance is the inability to tolerate a dose of statin required to reduce a person's CV risk sufficiently from their baseline risk and could result from different statin related side effects including: muscle symptoms, headache, sleep disorders, dyspepsia, nausea, rash, alopecia, erectile dysfunction, gynecomastia, and/or arthritis. The prevalence of statin intolerance is the subject of considerable discussion. It seems that this phenomenon might occur in $10-15 \%$ of patients [11, $12]$, however only very few $(<1 \%)$ develop serious side-effects such as myopathy, myositis or rhabdomyolysis [12]. In randomized controlled trials (RCTs), the incidence of statin myopathy is $\leq 5 \%$ (usually about 3\%) [13]. This low incidence is misleading for several reasons. In most studies patients with a history of any statin-related side effects were excluded. Moreover, patients who are at risk of developing muscle-related symptoms, such as women, elderly patients, and patients with significant comorbidities (e.g. liver failure, kidney failure or thyroid disease) are underrepresented in RCTs. In addition, some studies ignored statin-associated myalgia and only considered elevated serum creatine kinase (CK) activity as a side effect [14].

In clinical practice, statin intolerance limits effective treatment of patients at risk of, or with, CV disease (CVD). Physicians face the dilemma of whether to continue statins or use other lipid lowering drugs [10]. Knowledge of the most common adverse effects of statin therapy that might cause statin intolerance and the clear definition of this phenomenon is crucial to effectively treat patients with lipid disorders. Therefore, the aim of this position paper was to suggest a unified definition of 
statin intolerance, and to complement the recent EAS statement on SAMS, where both pathophysiology, diagnosis and the management were comprehensively presented [10].

\section{Statin-related adverse effects}

Statin toxicity became of general public interest in 2001, when cerivastatin was withdrawn from the market (52 deaths from rhabdomyolysis) although rhabdomyolysis was not observed in a meta-analysis of cerivastatin clinical trials [15, 16]. Such side effects can impair the quality of life, adherence to treatment, and in extreme cases, may lead to death. Therefore, uncovering the mechanisms by which statins might lead to side effects is of great urgency.

There is some disagreement whether cholesterol-lowering properties of statins might lead to their toxicity. According to available data, side effects are class-dependent, dose-dependent, time-dependent, age-, gender- and co-morbidity dependent, and/or dependent on co-treatment with certain drugs or foods (e.g. intake of grapefruit juice > $1 \mathrm{l} /$ day) $[10-14,17]$. Known risk factors (endogenous, exogenous) predisposing to clinically relevant side-effects include: highdose statin therapy, advanced age ( $>70$ years), female sex, family history of muscle disorders, history of CK elevation, vitamin D deficiency, renal and hepatic impairment, previous history of muscle toxicity with another lipid-lowering therapy, untreated hypothyroidism, disorders of calcium homeostasis, alcohol abuse, Asian ethnicity, low body mass index (BMI), genetic polymorphisms (e.g. genes associated with drug and muscle metabolism), surgery with severe metabolic demands, heavy and/or unaccustomed exercise and interactions with concomitant medication [18]. This has been extensively presented in the recent EAS statement on SAMS [10], however it might be useful to consider some of the populations at risk of statin intolerance in more detail (see below).

\section{Muscle-related side effects}

Statin-related side effects in $90 \%$ of all cases appear in first 6 months after initiation of the treatment or dose up-titration, and in about $75 \%$ in the first 10-12 weeks [19]. The most common statin-related adverse event is muscle weakness, however, due to the many potential reasons for this symptom, it is sometimes difficult to definitely state that it is indeed statin-related [10-13].

The clinical features of SAMS include symptoms such as muscle aches or myalgia, weakness, stiffness, and cramps [20]. According to the available data, statins might cause myalgia in $3-5 \%$ patients, myopathy in $0.1-0.2 \%$ and rhab- domyolysis in $0.01 \%$ patients $[13,20]$. Myopathy or myositis is usually defined as a diffuse muscle symptom that accompanies elevation of plasma CK activity 10-times higher than the upper limit of normal (ULN). It is generally marked by the presence of pain, tenderness, weakness due to severe pain and restriction in mobility. However, it is worth emphasizing that statin-associated myopathy may or may not be associated with elevations in CK activity. Patients with normal CK activity were also reported to develop myopathic symptoms with statin therapy, indicating that assessment of CK alone cannot adequately predict statin-associated myopathy [20, 21]. Muscle pain in patients taking statins could also occur due to the structural damage of muscle fibers in the absence of elevated CK activity. Rhabdomyolysis is characterized by marked elevation of CK activity > 50-fold, myoglobinemia, myoglobinuria, and myoglobin-induced acute renal failure (oliguria, increased plasma creatinine, potassium and phosphorus) [10, 20-22]. According to the National Lipid Association (NLA) clinical rhabdomyolysis has been defined as severe myonecrosis with myoglobinuria or acute renal failure (increase in serum creatinine $\geq 0.5 \mathrm{mg} / \mathrm{dl}$ ) $[10,20]$. It is a more aggressive and severe form of statin-induced myopathy, resulting in severe skeletal muscle injury, lysis, and excretion of dark brown urine (indicating presence of excess myoglobin) [18-20]. Rhabdomyolysis has an approximately $10 \%$ risk of death due to hyperkalemia-induced arrhythmias or disseminated intravascular coagulation [18-20].

There are also some differences concerning the prevalence of SAMS with different statin formulations [20]. According to the available data it seems that patients taking simvastatin, atorvastatin $(18.2,9.4-14.9 \%$ according to PRedlction of Muscular risk in Observational conditions (PRIMO) survey [23] and the Effects of Statins on Muscle Performance (STOMP) study [24], retrospectively) and lovastatin might be at the highest risk of SAMS. The risk of myopathy was suggested to be lowest with pravastatin (10.9\%) and fluvastatin (5.1\%), possibly because they are more hydrophilic and as a result have less muscle penetration [23]. Individuals on lovastatin, simvastatin (7 cases in the Study of the Effectiveness of Additional Reductions in Cholesterol and Homocysteine (SEARCH) Collaborative Group [25], and 7 in the Heart Protection Study 2-Treatment of HDL to Reduce the Incidence of Vascular Events (HPS2-THRIVE) trial [26]) and atorvastatin therapy reported higher incidences of rhabdomyolysis. This was due to higher rate of statin metabolism by hepatic microsomal enzymes, cytochrome P3A450 (CYP) isoenzymes. Concurrent use of statins with these medications 
M. Banach, M. Rizzo, P.P. Toth, M. Farnier, M.H. Davidson, K. Al-Rasadi, W.S. Aronow, V. Athyros, D.M. Djuric, M.V. Ezhov, R.S. Greenfield, G.K. Hovingh, K. Kostner, C. Serban, D. Lighezan, Z. Fras, P.M. Moriarty, P. Muntner, A. Goudev, R. Ceska, S.J. Nicholls, M. Broncel, D. Nikolic, D. Pella, R. Puri, J. Rysz, N.D. Wong, L. Bajnok, S.R. Jones, K.K. Ray, D.P. Mikhailidis

significantly increases the risk of rhabdomyolysis compared with monotherapy; the higher risk is more often reported in statin-fibrate combinations than in statin-niacin combinations [1820]. In general, these muscle effects have been reported more with the use of synthetic, potent and more lipophilic statins [18-20].

\section{Expert opinion}

The authors of this position paper support the recent EAS Consensus Panel Statement on Assessment, Aetiology and Management of statin-associated muscle symptoms (SAMS).

\section{Hepatotoxicity}

An asymptomatic rise in hepatic enzyme activity is one of the most common AEs of statin therapy - the incidence of elevated aminotransferase activity $>3$ times ULN is typically no greater than $3 \%$ [27]. The elevation of aminotransferases usually returns to normal after a dose reduction without the need for statin discontinuation (in some cases it is possible to return to the initial doses of statins after 2-4 weeks) [10-13].

Whereas statin-induced hepatotoxicity is rare but may be present as asymptomatic elevation of serum transaminases ( $0.5-2 \%$ of patients treated), hepatitis, cholestasis and acute liver failure. The proposed mechanisms of statin-induced hepatotoxicity include induction of caspase activity, triggering of apoptosis, reduction of coenzyme Q10 (ubiquinone, CoQ10) and generation of free radicals $[18,20]$. However, it is still not clear whether (and how) statins cause any kind of significant liver injury or liver failure. A recent analysis of the Swedish Adverse Drug Reactions Advisory Committee estimated the incidence of statin-related transaminitis at 1.2 per 100,000 patients taking statins. The liver abnormalities were mostly seen after 3 to 4 months of treatment, and atorvastatin and simvastatin were the most responsible agents [28]. Statin-induced jaundice is calculated at a risk of 1 in 17,434 users per year, based on a population in Iceland [29]. Periodic monitoring of liver enzyme activity seems not to be useful in either detecting or preventing serious liver injury, thus justifying the discontinuation of the previous recommendation for routine, serial liver enzyme monitoring during chronic statin therapy [30]. According to statement from $28^{\text {th }}$ February 2012 the Food and Drug Administration (FDA) recommends checking liver function tests at baseline and later as clinically warranted [31].

\section{Expert opinion}

The authors of this position paper support FDA recommendation to analyze aminotransferases before starting statin therapy and as clinically indicated thereafter (e.g. if AEs appear during the therapy).

\section{New onset diabetes mellitus}

Statin therapy may increase the risk of NOD; this association is observed for all investigated statins (hydrophilic or lipophilic), thus possibly representing a class effect $[32,33]$. At least few mechanisms may contribute to causing NOD associated with statin therapy [34]. In recent years there has been a debate regarding the clinical implications of this phenomenon - whether and when we should start treatment, in what groups we should continue, stop it, or reduce the statin dose, and which groups of patients are at the highest risk of NOD [33, 35].

This debate began few years ago after the publication of the meta-analysis [36], which revealed that statin therapy for a mean follow-up of 4 years was associated with a higher incidence (by $9 \%$ ) of NOD. The risk of development of NOD with statins was highest in trials with older participants, but neither baseline BMI nor change in low density lipoprotein cholesterol (LDL-C) concentrations accounted for variation in risk [36]. The next meta-analysis reported an even higher $-13 \%$ increase in the risk of NOD [37]. Preiss et al. in their meta-analysis [38] concluded that although high-dose statin therapy compared with moderate-dose statin therapy was associated with a higher incidence of NOD (by $12 \%$ ), it was also related to significant reduction in major CV events (by $16 \%$ ). They showed that intense statin treatment is beneficial since it significantly outweighs the risks of NOD. There was one additional case of type 2 diabetes mellitus (T2DM) for every 498 patients treated for 1 year compared with 1 fewer patient experiencing a CV event for every 155 patients treated for 1 year [38]. The benefits of statin therapy, which outweighs NOD risk, have been also observed in the primary prevention studies. The analysis of the Justification for the Use of Statins in Prevention: an Intervention Trial Evaluating Rosuvastatin (JUPITER) study [39] demonstrated that in participants with and without diabetes risk factors, the overall beneficial effect of statin therapy on vascular events was greater (almost 2.5 -fold) than the hazard of developing NOD, and this effect was observed even in a lower-risk primary-prevention population [39]. On the basis of the available data FDA presented the communications warning that statin therapy had been 
associated with increases in levels of fasting serum glucose and $\mathrm{HbA}_{1 \mathrm{c}}[31,40]$.

\section{Expert opinion}

For patients on statin therapy, there are no reasons to stop taking statins (even if NOD is diagnosed), however careful risk stratification before introducing statin therapy should always be performed.

Statins should be used in secondary prevention patients, as the CV benefits significantly outweigh the risk of NOD.

There has been a debate whether statins should be used for primary prevention among patients with a relatively low baseline CV risk. In this group of patients introducing statins should be considered individually after careful estimation of $\mathrm{CV}$ risk and treatment adverse events risks, when non-pharmacological therapy is not effective.

\section{Other rare statin-associated adverse effects}

Despite the fact that SAMS are the most common observed adverse effects, patients on statins may also present with other side effects, which might reduce their quality of life, and might require a reduction of dose or statin discontinuation [41].
It has been reported that these AEs may affect less than 1 in 100 people. The most common observed statin-related side effects with the information on their prevalence are presented in Table I.

\section{Conditions and populations at high risk of statin intolerance}

\section{Physical activity and statin intolerance}

Regular physical activity has advantageous effects on the CV system and reduces CVD mortality $[72,73]$. However, problems (muscle pain, increased CK activity) may occur when statins are prescribed for patients taking regular exercise (e.g. sportsmen), or when patients start healthy lifestyle, including physical exercise, according to recommendations [74-76]. In the PRIMO survey, the prevalence of statin myopathy was $14.7 \%$ in those undergoing physical activity and $10.8 \%$ in less active subjects [23]. The Boston marathon runners on statins had much higher CK levels and enhanced susceptibility to muscle injury during exercise, than those not taking statins [77]. Thompson et al. also noticed that statin therapy might exacerbate exercise-induced skeletal muscle injury even after less intense training (45 min of downhill treadmill walking (-15\% grade) at $65 \%$ of their predetermined maximum heart rate) [78].

Table I. Statin-related side effects that have been described in the literature

\begin{tabular}{|c|c|}
\hline Organ/systems & Side-effects of statins \\
\hline Respiratory & $\begin{array}{l}\uparrow \text { Risk of interstitial lung disease by } 0.01-0.4 \% \text { [ } 42] \\
\uparrow \text { Risk of upper respiratory tract infection by } 1-16 \% \text {, } \uparrow \text { risk of pharyngitis by } 3-13 \% \text {, rhinitis } \\
\text { by } 1-11 \% \text {, sinusitis by } 2-7 \% \text {, bronchitis by } 2 \% \text {, cough by } 1-2 \% \text { [43] }\end{array}$ \\
\hline $\begin{array}{l}\text { Neurologic and } \\
\text { psychological } \\
\text { effects }\end{array}$ & $\begin{array}{l}\uparrow \text { Risk of suicide [44], aggressive behavior [45] } \\
\uparrow \text { Headache by } 2-17 \% \text {, asthenia by } 1-4 \% \text {, dizziness by } 1-4 \% \text {, fatigue by } 1-4 \% \text { [43] } \\
\uparrow \text { Risk of depressive disorder in stroke patients [46] } \\
\uparrow \text { Risk of hemorrhagic stroke (adjusted hazard risk (HR) } 1.66,95 \% \mathrm{Cl}: 1.08-2.55) \text { [47] } \\
\text { Severe irritability [48], insomnia, somnolence, agitation, confusion, hallucinations [49] and } \\
\text { nightmares [50] }\end{array}$ \\
\hline Endocrine & $\begin{array}{l}\uparrow \text { Risk of NOD from } 9-27 \%[36,38,39,51] \\
\text { Intensive-dose statin therapy is associated with a } 12 \% \text { higher incidence of NOD compared } \\
\text { with moderate-dose statin therapy }[38,51]\end{array}$ \\
\hline $\begin{array}{l}\text { Gastrointestinal } \\
\text { tract }\end{array}$ & 个 Constipation, diarrhea, dyspepsia, flatulence heartburn, nausea vomiting [43] \\
\hline Hepatic & $\begin{array}{l}<1.5 \% \text { hepatotoxicity in coronary artery disease patients in } 5 \text { years [1] } \\
\uparrow \text { Activity of liver enzymes }[27,28]\end{array}$ \\
\hline Skin & $\begin{array}{l}\uparrow \text { Risk of alopecia [52], lichenoid eruption [53], dermographism [54], chronic urticaria [55], } \\
\text { toxic epidermal necrolysis [56] and rash by } 1-4 \% \text { [57] }\end{array}$ \\
\hline Eye & $\begin{array}{l}\uparrow \text { The risk of cataract by } 27 \%[58] \\
\uparrow \text { Diplopia, ptosis and ophthalmoplegia [59] }\end{array}$ \\
\hline Renal & $\uparrow$ Risk of acute renal failure [60], $\uparrow$ proteinuria [61] \\
\hline Reproductive & $\begin{array}{l}\text { Erectile dysfunction [62], decrease libido [63], gynecomastia [64], } \downarrow \text { testosterone levels } \\
\text { by } 10.3 \% \text { and by } 7.5 \% \text { respectively after } 48 \text { weeks of statins [65] }\end{array}$ \\
\hline Blood & $\uparrow$ Risk of thrombotic thrombocytopenic purpura (TPP) [66-68] \\
\hline Bones and joints & Tendinitis, arthralgia, arthritis, lupus, polymyalgia rheumatica [69-71] \\
\hline
\end{tabular}


M. Banach, M. Rizzo, P.P. Toth, M. Farnier, M.H. Davidson, K. Al-Rasadi, W.S. Aronow, V. Athyros, D.M. Djuric, M.V. Ezhov, R.S. Greenfield, G.K. Hovingh, K. Kostner, C. Serban, D. Lighezan, Z. Fras, P.M. Moriarty, P. Muntner, A. Goudev, R. Ceska, S.J. Nicholls, M. Broncel, D. Nikolic, D. Pella, R. Puri, J. Rysz, N.D. Wong, L. Bajnok, S.R. Jones, K.K. Ray, D.P. Mikhailidis

The cross-sectional analysis of over 10,000 patients showed that increased physical fitness and statin therapy are independently associated with decreased mortality, but an accumulation advantage on premature mortality through combination of statin therapy and exercise training was observed [79].

The mechanisms responsible for these associations are poorly understood. In an animal model of statin-induced myopathy, administration of simvastatin impaired phosphatidylinositol 3-kinase (PI3k)/Akt signaling in muscle, inducing ubiquitin and lysosomal proteolysis through up-regulation of the FOXO downstream target genes of muscle atrophy such as cathepsin-L mRNA, muscle RING finger-1 (MuRF-1), and F-box (MAFbx), and dephosphorylation of the forkhead box protein O (FOXO) (1 and 3) transcription factors [80]. In skeletal muscle tissue statin therapy can cause mitochondrial dysfunction limited typically to complex I of the respiratory chain, which increases mitochondrial NADH and the intracellular redox potential (NADH/NAD ${ }^{+}$ratio), activates pyruvate dehydrogenase kinase (PDK), and inhibits flux via the pyruvate dehydrogenase complex (PDC) [81, 82]. Another possible mechanism for statin-induced myopathy during exercise might be the down-regulation of atrogin-1 gene expression, a critical component of the ubiquitin proteasome pathway and of muscle protein catabolism [83]. Inflammation, exercise-induced irisin secretion, a myokine modulating the impact of exercise on adipocyte browning, reduced sarcolemmal or endoplasmic reticulum cholesterol, depletion of intracellular cholesterol leading to increased calcium influx, increased myocellular concentrations of cholesterol and plant sterols, modified signal transduction and metabolism due to decreased mevalonic acid and its metabolite concentrations as well as vitamin D deficiency or coenzyme Q10 deficiency might also increase the probability of statin therapy influence on the capacity of skeletal muscle to conform to the stress of exercise training $[84,85]$.

The studies, which analyzed the risk and benefits of combining statins and exercise, are limited. Using a new approach that lower statin dosage to permit uncompromised exercise training might be a solution for these patients [27]. However, there are at least few questions that need to be addressed in future studies. First, how to manage patients on intensive regular training (or sportsmen) with high CV risk who require moderate- to high-intensity statin therapy. Second, whether we should discontinue statin therapy or reduce the dose before intense exertion [86].

\section{Expert opinion}

In individuals with regular intense physical exertion one should consider low to moderate-intensity statin therapy.

In patients on statin therapy, the reduction of dose or therapy discontinuation should be considered for at least 2 days before predicted intense physical exertion. Any such decision should be balanced with the risk of discontinuing statins.

\section{Thyroid diseases and statin intolerance}

Statin treatment in the presence of hypothyroidism increases the risk of skeletal muscle toxicity [87]. These unwanted effects of statins do not correlate with the degree of cholesterol lowering effect of the compound used (drug class effect) but are dose-related $[87,88]$, and are related to the impairment of mitochondrial function and muscle calcium homeostasis [89].

Data from the National Health and Nutrition Examination Survey (NHANES) indicates that hypothyroidism occurs in $0.3-0.4 \%$ persons in the US, while subclinical hypothyroidism may occur in $4.3-8.5 \%$ of the general population [90]. It has been shown in an animal model that hypothyroidism promotes an increase in oxygen consumption by skeletal muscle mitochondria and induces an increase in sarcoplasmic reticulum calcium [91]. Thus, hypothyroidism predisposes to statin-induced muscle toxicity and substantially increases the risk of muscle symptoms through the same mechanisms as in "non-thyroid" patients [91].

Given that patients with hypothyroidism have been excluded from statin clinical trials there are limited data regarding the incidence of statin muscle toxicity in patients with hypothyroidism [92-97]. In hypothyroid patients, myopathy with mild elevation of serum CK activity is not rare and in a few cases might take the form of overt rhabdomyolysis even in patients not on statin treatment. However, if statin treatment is added it seems that the risk of muscle-related side effects increases markedly [91-97]. It is therefore recommended that a clinical examination, thyroid-stimulating hormone (TSH) and thyroxine levels measurement should be performed before statin treatment initiation. This is in agreement with the recent ACC/AHA lipid guidelines, which suggests that the patients prior to statin treatment initiation should always be evaluated for factors that might increase the risk for muscle symptoms (e.g. hypothyroidism) [1]

If TSH is $>10 \mathrm{mIU} / \mathrm{l}$ statins should not be prescribed until TSH returns to levels $<4 \mathrm{mIU} / \mathrm{l}$, after thyroxine administration [98]. Given that hypothyroidism is the second most incident cause of 
secondary dyslipidemia, there might be no need for statin treatment after effective thyroxine treatment. Hypothyroidism might also emerge during long-term statin treatment [99]. In this case affected patients might develop symptoms or signs suggestive of myopathy attributed in most cases to statin therapy [99]. These patients should be tested for hypothyroidism again and discontinue statin treatment [99].

Data suggests that subclinical hypothyroidism (SCH) (TSH levels > 4 and $<10 \mathrm{mIU} / \mathrm{l}$ ) is related to an unfavorable lipid profile, and levothyroxine replacement therapy may also be prescribed in these patients [100]. Some data suggest that levothyroxine replacement therapy may exert a beneficial effect on total cholesterol (TC), LDL-C and other predictors of vascular risk in $\mathrm{SCH}$ [100]. Furthermore, it appears that in $\mathrm{SCH}$, statins with or without levothyroxine, can improve endothelial function and reduce carotid intima media thickness, reliable markers associated with CVD risk [101]. However, statins may be related to muscle symptoms even in patients with SCH [102]. In most cases the clinical characteristics are mild, and patients may only exhibit raised muscle enzyme activities or symptoms of mild myalgia and myopathy [102], which usually improve after statins discontinuation [7]. Nevertheless, there have been reports of severe rhabdomyolysis associated with acute renal failure requiring renal replacement therapy after using high-dose statins in a patient with $\mathrm{SCH}$ [102].

\section{Expert opinion}

A clinical evaluation and TSH and thyroxine should be performed at baseline prior to starting statin treatment.

Clinical (TSH > $10 \mathrm{mIU} / \mathrm{l}$ ) or subclinical (TSH = 4-10 mIU/l) hypothyroidism requires thyroxine substitution treatment for at least 3 months, with TSH normalization; if there is residual dyslipidemia and statin therapy is necessary this could be introduced after thyroid function normalization.

\section{Alcohol consumption and statin intolerance}

Currently there is limited data on the adverse effects of alcohol consumption on statin treatment. The majority of patients on statins do not abuse alcohol. It was shown that alcohol misuse was associated with increased risk for statin non-adherence $[103,104]$. It can be assumed that high doses of alcohol provoke liver dysfunction and increase the risk of myopathy in patients on high-intensity statin therapy [104]. However, in the Post-Coronary Artery Bypass Graft (CABG) trial all patients were randomly assigned to lovas- tatin in low (mean $4 \mathrm{mg}$ ) or high (mean $76 \mathrm{mg}$ ) doses, and were categorized by weekly alcohol intake to abstinent ( $<1$ drink), light (1-6 drinks), moderate (7-13 drinks), and heavy ( $\geq 14$ drinks) drinkers. During follow-up only $7 \%$ of men had an alanine aminotransferase (ALT) of $80 \mathrm{IU} / \mathrm{l}$ or higher. The risk of an ALT of 80 IU/I or more was comparable between these groups: $8,10,9$, and $6 \%$ $(p=0.70)$, respectively [105].

In a small randomized study involving 26 individuals with primary hypercholesterolemia, $20 \mathrm{~g}$ of alcohol tended to increase the half-life, area under the curve and the time to reach maximum concentration of fluvastatin at a dose $40 \mathrm{mg} /$ day [106]. Most statins are metabolized via cytochrome P450 3A4 (CYP3A4); rosuvastatin is principally metabolized via CYP2C9 whereas ethanol is converted to acetaldehyde by CYP2E1 [107]. Therefore, it seems that there is no clear basis for significant pharmacokinetic interaction between alcohol and statins in humans.

\section{Expert opinion}

To reduce the risk of statin intolerance all dyslipidemic patients should follow the European guidelines on cardiovascular disease prevention in clinical practice (2012) [108]: "Consumption of alcoholic beverages should be limited to 2 glasses/day (20 g/day of alcohol) for men and $1 \mathrm{glass} /$ day (10 g/day of alcohol) for women to obtain the lowest level of chronic disease risk".

\section{Liver diseases and statin intolerance}

The administration of statins to patients with liver diseases has been the forbidden fruit of lipidology for at least 2 decades. This impression was based on the belief that statins are hepatotoxic, even in the general population, manifested as an increase in serum ALT or aspartate aminotransferase (AST) activities, requiring statin dose reduction or discontinuation [109]. During the last decade it was established that ALT elevations > 3 times ULN occur in $<0.5 \%$ for moderate-dose statins and rosuvastatin at all doses, and about $1 \%$ for $80 \mathrm{mg}$ of atorvastatin or simvastatin [110]. However, even this might be an overstatement, because in most studies, the incidence of ALT increase was similar in statin and placebo patients, and because of the fact that almost $50 \%$ of dyslipidemic patients requiring statin treatment, might have had established non-alcoholic fatty liver disease (NAFLD) $[111,112]$. For over 20 years a raised ALT during statin treatment has been also incorrectly considered to represent liver disease, which led to a lack of statin treatment in high risk CV patients [113]. Due to the abovementioned consideration, in 2012 the FDA suggested that patient follow-up for 
M. Banach, M. Rizzo, P.P. Toth, M. Farnier, M.H. Davidson, K. Al-Rasadi, W.S. Aronow, V. Athyros, D.M. Djuric, M.V. Ezhov, R.S. Greenfield, G.K. Hovingh, K. Kostner, C. Serban, D. Lighezan, Z. Fras, P.M. Moriarty, P. Muntner, A. Goudev, R. Ceska, S.J. Nicholls, M. Broncel, D. Nikolic, D. Pella, R. Puri, J. Rysz, N.D. Wong, L. Bajnok, S.R. Jones, K.K. Ray, D.P. Mikhailidis

liver tests are largely irrelevant when prescribing statins [31]. Nevertheless, the Liver Expert Panel recommends that patients with acute liver disease (e.g. acute viral hepatitis, alcoholic hepatitis) should not take statins until they have recovered $[109,114]$. In chronic liver disease (CLD) however, the experts suggested that the positive effect of statin therapy on the halt or even the regression of fibrosis or/and cirrhosis, should be further investigated [109, 114]. Both CLD and CVD are common and often overlapping that it is inevitable for clinicians to deal with the issue of whether or not to prescribe statins in patients with CLD, without causing liver-related statin intolerance.

\section{Hepatitis B (HBV) and C virus (HCV) liver disease}

Statins should not be prescribed to patients with active acute HBV until they have recovered from the acute phase and until the serum levels of AST, ALT, total bilirubin and alkaline phosphatase (ALP) have returned to normal [109, 114]. Patients with chronic HBV with indications for statin therapy should be treated $[109,114]$, however it is recommended to check liver enzymes 2 weeks after prescribing a statin or changing its dose, then monthly for 3 months and thereafter, 4 times a year [114]. Statins are rarely responsible for acute liver failure (ALF) - e.g. the use of lovastatin was reported to be related with ALF in $1 / 1.14$ million patient-treatment years, what is similar to the rate of idiopathic ALF $[114,115]$. Statin treatment might be useful in significantly reducing the risk of hepatocellular carcinoma (HCC) (even by $28 \%$ ) [116]. Thus, statin use in patients with HBV that have a very increased risk of HCC, might substantially reduce this risk.

Every year, 3-4 million people are infected with the HCV and about 150 million people are chronically infected with HCV worldwide, while more than 350,000 people die every year from hepatitis C-related liver diseases [117]. It has been shown that statin treatment in patients with chronic HCV infection may contribute to the clearance of the virus from the blood [118]. A strong relationship between HCV replication and lipid metabolism exists and statins are expected to disrupt this association [118]. It has been shown that fluvastatin down-regulated HCV replication in cell culture [119]. The levels of miRNA 122, which is a key regulator in liver homeostasis and provides HCV genomic stability remained at steady state whereas DCLK1 mRNA levels were considerably reduced during fluvastatin treatment. This was important because HCV replication was increased with DCLK1 overexpression [119]. It has been also shown that the combination of statins (except pravastatin) with interferon exhibited strong inhibitory effects on HCV RNA replication [120]. This was the first time when statins, especially fluvastatin, were shown to be potentially useful as new anti-HCV agents in combination with interferon [120], and that was confirmed in other studies [121]. Statin use (especially simvastatin, lovastatin and atorvastatin) in HCV patients is also associated with a $28 \%$ decrease in risk of HCC. This was shown in a study that included 3,480 patients with recently diagnosed HCC and 13,920 control subjects without HCC matched for age, sex and follow-up length [119]. A systematic review and meta-analysis that included 10 studies reporting 4,298 cases of HCC in 1,459,417 patients showed a $33-51 \%$ adjusted HCC relative risk reduction in statin users compared with statin abstainers [122]. Similar results (up to $48 \%$ HCC risk reduction) were obtained in another meta-analysis [123].

The use of statins prevents about 33\% of major CVD events when compared with placebo; the number needed to treat (NNT) is 3 [124, 125]. Statins may cause serious liver disease, in $1 / 1,000,000$; the number needed to harm (NNH) is 1 million [118]. The percentage of patients who fail to receive statins because of fear of hepatotoxicity ranges between 10-30\% [126]. On the other hand statins contribute to the clearance of viral hepatitis [120-122], and substantially reduce the risk of HCC $[119,122,123]$. Thus, the fear of a possible drug adverse effect, which is extremely rare, might be a reason that many patients needlessly suffer or die from cirrhosis, HCC or CVD events [126]. Moreover, $7 \%$ to $29 \%$ of liver transplantation candidates are denied listing as potential recipients because of CVD [127]; they may have been eligible for listing if they had been on statin therapy [127].

\section{Primary biliary cirrhosis (PBC)}

Total cholesterol and LDL-C levels are usually elevated in the patients with PBC. The issue is whether or not this is indeed a CVD risk factor and whether it should be treated [128]. Available data suggests that high LDL-C in patients with PBC should be considered as a CVD risk factor in a subgroup of patients with other CVD factors [128]. It was shown that low-dose atorvastatin therapy is safe at early-stage PBC, effectively reducing TC and LDL-C, oxidized LDL and soluble vascular cell adhesion molecule-1 (VCAM-1); moreover, it improves vascular function as reflected by flow mediated dilatation (FMD), without affecting PBC progression [129]. It was shown, that simvastatin therapy in patients with $\mathrm{PBC}$ is safe and effective in reducing $T C$ and $L D L-C$, also having advantageous effects on endothelial function and antioxidant status [130]. Thus, statins should be considered in PBC patients with additional CVD risk factors or overt CVD [129]. Available data has also suggested 
that statins might have a beneficial effect on PBC itself [128-131].

\section{Non-alcoholic fatty liver disease (NAFLD) and steatohepatitis (NASH)}

NAFLD is associated with hypertriglyceridemia and reductions in high density lipoprotein cholesterol (HDL-C) levels, which may be secondary to an increase in the size of very low density lipoproteins (VLDL) and LDL particle size/atherogenicity [132]. Therefore, in NAFLD patients statin therapy should be recommended. This was a considerable problem in the past because physicians were afraid of liver damage if they prescribed statins [133]. Therefore, until recently there has been no effective treatment for NAFLD/ NASH [134]. In a post hoc analysis of the GREek Atorvastatin and Coronary heart disease Evaluation (GREACE) study assessed patients with established CVD and elevated ALT activity due to NAFLD [135]. Atorvastatin treatment (mean dose $24 \mathrm{mg} /$ day) improved transaminase activity as well as the hepatic ultrasound features during the 3-year follow-up [135]. This suggested that NAFLD resolved in most statin-treated CVD patients in contrast to those not on a statin, in whom NAFLD worsened during the 3-year follow-up [135]. Atorvastatin also reduced CVD morbidity/mortality in patients with abnormal transaminase activity due to NAFLD to a greater extent than in those on atorvastatin, but without NAFLD (68 vs. 39\%, $p=0.007$ ) [135]. A similar level of safety, NAFLD resolution and CVD benefit of atorvastatin treatment was recorded in other categories of high risk patients (with dyslipidemia, metabolic syndrome, hypertension or smoking), both in primary and secondary CVD prevention [136-138]. In the prospective St Francis Heart Study 1,005 participants (50-70 years old) were randomized to receive either atorvastatin $20 \mathrm{mg}$, vitamin $\mathrm{C} 1 \mathrm{~g}$, and vitamin E 1,000 IU or placebo [139]. The results showed that atorvastatin, combined with antioxidant vitamins, significantly reduced the risk hepatic steatosis by $71 \%$ in healthy individuals with NAFLD at baseline during a 4-year follow-up [139]. The post hoc analysis of the Incremental Decrease in End Points Through Aggressive Lipid Lowering (IDEAL) study, compared intensive (80 mg of atorvastatin) vs. moderate $(20-40 \mathrm{mg}$ / simvastatin) statin therapy in CVD patients with normal or elevated baseline ALT activity [140]. The results showed that in patients with moderate elevations of ALT activity statins were safe and reduced ALT activity by $13.4 \pm 27.5 \mathrm{IU} / \mathrm{I}$ in those on atorvastatin $80 \mathrm{mg} /$ day $(p<0.0001)$ and $8.8 \pm 28.8 \mathrm{IU} / \mathrm{I}(p=0.007)$ in those on simvastatin $20-40 \mathrm{mg} /$ day [140].
All the above suggest that moderate elevations in liver enzyme activity in high CVD risk patients should not be a barrier to prescribe statins, possibly even at higher doses. Physicians are still afraid of using statins in NAFLD patients. This approach should be changed for at least two reasons: one is that statins seem to be an acceptable treatment of NAFLD itself (at least in patients with dyslipidemia, which includes the vast majority of NAFLD patients), and second because NAFLD patients are exposed to increased CVD risk and they seem to benefit from statin therapy more than those without NAFLD [141]. Finally, it is important to the note that more NAFLD patients die of a vascular cause than a hepatic cause [142].

\section{Expert opinion}

The authors of this position paper recommends more frequent ALT/AST monitoring in patients with CLD: every month during the first 3 months of therapy and 4 times per year thereafter.

In CLD patients we recommend stopping statin therapy if AST/ALT activities rise $\geq 2$ times the baseline value. After AST/ALT activities return to normal/baseline values, it is recommended to consider another statin in order to establish whether patient is (liver) statin intolerant.

With regard to $H B V, H C V$ and $P B C$, there are common benefits related to statin therapy in high risk CV patients. Statins also confer a more efficient treatment of viral hepatitis and it is related with reduced risk of cirrhosis and HCC.

In patients with NAFLD/NASH statin treatment is safe, contributes to the resolution of NAFLD/NASH, and substantially reduces CVD risk to a level higher than in those with normal liver function.

\section{Kidney diseases and statin intolerance}

The Task Force for the management of dyslipidemias of the ESC/EAS included pre-existing renal disease among the clinical factors that predispose patients to a higher incidence of statin intolerance [27]. Moreover, the presence of dyslipidemia in these patients might enhance the rate of decline in renal function and chronic kidney disease (CKD) progression, generally by raising the inflammation and the oxidative stress in the renal microenvironment [143-146]. In the post-hoc analyses of randomized controlled trials (RCTs) the benefits of statins in myocardial infarction (MI) also extend to patients with mild-to-moderate renal insufficiency [147], but these patients are more prone to CVD than progress to end-stage kidney disease [147]. 
M. Banach, M. Rizzo, P.P. Toth, M. Farnier, M.H. Davidson, K. Al-Rasadi, W.S. Aronow, V. Athyros, D.M. Djuric, M.V. Ezhov, R.S. Greenfield, G.K. Hovingh, K. Kostner, C. Serban, D. Lighezan, Z. Fras, P.M. Moriarty, P. Muntner, A. Goudev, R. Ceska, S.J. Nicholls, M. Broncel, D. Nikolic, D. Pella, R. Puri, J. Rysz, N.D. Wong, L. Bajnok, S.R. Jones, K.K. Ray, D.P. Mikhailidis

The efficacy of statins in dialysis or severe renal insufficiency patients following a MI is less known, although statins have not been proven to modify the main CV and mortality outcomes in primary prevention in hemodialysis patients [148]. Dormuth et al. evaluated the association between the potency of statins and acute kidney injury (AKI) and noticed 34\% higher rate of hospitalization for AKI in the participants on higher compared with lower doses of statins during the first 120 days of treatment [149]. A recent meta-analysis, which included 9 RCTs with 5212 patients with and without acute coronary syndrome evaluated the potential of statins in prevention of contrast-induced acute kidney injury (Cl-AKI). The results proved that pre-procedural, short-term intensive statin therapy substantial reduced $\mathrm{Cl}-\mathrm{AKI}$ in $\mathrm{ACS}$ patients, but the role of statins in non-ACS patients still requires further exploration [150].

Patients with CKD might have increased susceptibility to develop statin intolerance since multiple abnormalities like endothelial dysfunction, enhanced oxidative stress, systemic inflammation, electrolyte imbalances, or proteinuria are simultaneously present [151, 152]. Recent Kidney Disease: Improving Global Outcomes (KDIGO) guidelines regarding the use of cholesterol lowering medications in adults and children with known CKD stated the potential benefits of a new strategy named fire-and-forget for CKD patients, suggesting not to measure LDL-C unless the results would alter management [153]. In other words, physicians may choose to perform follow-up measurement of lipid levels in patients for whom these measurements are judged to favorably influence adherence to treatment or other processes of care [153]. Moreover, KDIGO guidelines recommended statin or statin/ezetimibe therapy in all individuals aged $\geq 50$ years with $\mathrm{eGFR}<60 \mathrm{ml} / \mathrm{min} / 1.73 \mathrm{~m}^{2}$, and not recommend initiation of statin therapy in dialysis or kidney transplantation patients [153]. Finally, concerning the safety of the statin therapy, the KDIGO Work Group suggests that, due to lack of evidence that the risk of liver dysfunction differs in people with CKD, as compared with those without, baseline levels of transaminases should be measured before initiating statin treatment, however routine follow-up measurements are not recommended [153]. Similarly, they do not recommend measurement of CK activity at baseline or during follow-up, unless the patient develops symptoms suggestive of myopathy [153].

\section{Expert opinion}

Patients with CKD are at higher risk of statin intolerance due to several abnormalities, including endothelial dysfunction, enhanced oxidative stress, systemic inflammation, electrolyte imbalances, proteinuria, as well as use of concomitant therapies.

The authors of this position paper support the KDIGO guidelines on statin safety in CKD patients and recommends measurements of baseline ALT/ASP activity before initiating statin treatment without follow-up measurements, and do not recommend measurements of $C K$ activity at baseline or during follow-up, unless the patient develops symptoms suggestive of myopathy.

\section{Elderly patients and statin intolerance}

Aging causes changes in drug pharmacokinetics and pharmacodynamics, which may increase drug concentration in elderly patients, increasing the risk of adverse effects [154, 155]. Physiologic changes with aging include absorption, distribution, metabolism and excretion [154]. With aging, there is a decrease in lean body mass and in total body water, causing a reduction in volume of distribution $\left(V_{d}\right)$ of hydrophilic drugs [156]. This causes higher plasma concentrations of hydrophilic drugs in the elderly [154]. The increased proportion of body fat that occurs with aging also causes an increased $V_{d}$ of lipophilic drugs [154]. The level of $\alpha 1$-acid glycoprotein increases, and plasma albumin concentration tends to be reduced in the elderly [157]. Reduced liver mass, hepatic blood flow, and hepatic metabolic capacity observed in the elderly causing accumulation of metabolized drugs [154]. Additionally decreased GFR, renal tubular function, and renal blood flow is a reason of accumulation of drugs cleared by the kidney [154]. Changes in $V_{d}$ and/or clearance due to aging can affect the half-life of a drug, and an increased halflife means a longer time until steady state conditions occur [154]. There might also be an initial delay for the maximum effects of the drug to occur and prolonged adverse effects [154]. Impaired hemostasis, reduced chemoreceptor and baroreceptor sensitivity, and reduced $\beta$-receptor sensitivity, as well as comorbidities and multiple medications are other major factors that might influence drug effects in elderly patients [154-157].

Differences in statin metabolism also influence potential drug interactions [158]. Atorvastatin, lovastatin, and simvastatin are metabolized primarily by the isoenzyme P3A4 of cytochrome P450 [158]. Inhibitors of cytochrome P3A4 (CYP3A4), which may lead to statin-associated adverse effects (and statin intolerance) include, among 
other, amiodarone, cimetidine, clarithromycin, cyclosporine, danazol, erythromycin, diltiazem, fluconazole, fluoxetin, fluvoxamine, gemfibrozil, grapefruit juice, indinavir, itraconazole, ketoconazole, metronidazole, nefazodone, nelfinavir, niacin, ritonavir, verapamil, voriconazole and zafirlukast [158]. When administered with verapamil or amiodarone, the maximum daily dose of simvastatin used should be $20 \mathrm{mg}$ to minimize the risk of myopathy [158]. When administered with cyclosporine, danazol or gemfibrozil, the maximum daily dose of simvastatin used to minimize the risk of myopathy should be only $10 \mathrm{mg}$ [158]. Bleeding or prolonged prothrombin time has been reported in patients taking statins metabolized by CYP3A4 treated concomitantly with warfarin [158]. Rhabdomyolysis and acute renal failure may possibly be caused by administering drugs, which inhibit CYP3A4 such as cyclosporine, gemfibrozil, niacin, and erythromycin, to elderly patients on statins metabolized by CYP3A4 [154]. Rosuvastatin has minimal metabolism by CYP2CP and CYP2C19 and has biliary excretion [159]. Pravastatin is metabolized by sulphation, biliary excretion, and urinary excretion [159]. Fluvastatin is metabolized by CYP2C9, CYP2C8, and CYP3A4, and inhibitors of CYP2C9 seem to be the most important in increasing myopathy risk in patients treated with fluvastatin [159]. Pitavastatin has minimal metabolism by CYP2C8 and CYP2C9 and has lactonisation and biliary excretion [159].

In elderly persons, the hydrophilic statins (pravastatin and rosuvastatin) are more likely to reach increased serum levels. The lipophilic statins are likely to cause increased availability because of the prolonged half-life caused by an increased proportion of total body fat [160]. A reduction in hepatic blood flow in elderly persons and a reduction in oxidative metabolism through the cytochrome P450 system in elderly persons may result in reduced clearance of many drugs leading to increased serum levels of drugs and associated toxicity [160]. Statins metabolized through pathways other than CYP3A4 may have fewer drug interactions and adverse effects in the elderly [160].

In the Heart Protection Study (HPS) 5,086 of the 20,536 men and women were aged 70 to 80 years at study entry [161]. Muscle symptoms were observed in only $0.5 \%$ of patients treated with simvastatin vs. $0.5 \%$ treated with placebo [161]. Rhabdomyolysis developed in this study in 5 of 10,269 persons $(0.05 \%)$ treated with simvastatin vs. 3 of 10,267 persons (0.03\%) treated with placebo. Statin discontinuation because of elevated liver enzymes was observed in $0.5 \%$ of patients treated with simvastatin vs. $0.3 \%$ treated with placebo [161]. In the Pravastatin in elderly individuals at risk of vascular disease (PROSPER) trial,
5,804 men and women were aged 70 to 82 years at study entry [162]. Study drug discontinuation because of adverse effects was similar in persons treated with pravastatin or placebo. No person developed rhabdomyolysis or a CK activity increased 10 times the ULN [162]. In older persons in the Treating to New Targets (TNT) trial the incidence of a $>3$ times increase in aminotransferase above normal was $1.3 \%$ in persons treated with atorvastatin $80 \mathrm{mg}$ daily vs. $0.1 \%$ in the group with atorvastatin $10 \mathrm{mg} /$ day [163]. No person developed a serum CK activity increased 10 times the ULN [163]. A meta-analysis of RCTs on the efficacy and safety of statin monotherapy in 51,351 patients showed no significant difference in study drug discontinuation between patients treated with statins vs. placebo [164]. Musculoskeletal complaints were present in $27 \%$ of patients treated with statins vs. $26 \%$ of patients treated with placebo $(p<0.01)$. ALT/ASP level > 3 times ULN was present in $0.5 \%$ treated with statins vs. $0.4 \%$ treated with placebo, and serum CK activity increased 10 times the ULN was present in $0.1 \%$ treated with statins vs. $0.1 \%$ treated with placebo ( $p>0.05$ for both) [164]. However, as it has been mentioned above, in all these trials most patients with any statin associated AEs were excluded during the recruitment period.

Because increased adverse effects from statins may occur in the elderly due to many different factors and conditions, one must be cautious in using the highest dose of statins in elderly patients [165]. Since 2011 the FDA has not recommended simvastatin $80 \mathrm{mg}$ daily because of the increased risk of myopathy, including rhabdomyolysis [1]. Hydrophilic statins may penetrate muscle tissue less than lipophilic statins and may be less likely to cause myopathy in elderly patients $[165,166]$. If severe illness, major surgery, or major trauma occurs in an elderly person, it is prudent to stop statin therapy until the person recovers [165]. However, it should be also emphasized, that any such decision should be carefully balanced with the risk of discontinuing statins [86].

Statin therapy is generally well tolerated in the elderly and is associated with a reduction in major CV events $[155,167]$. However it needs to be emphasized that in the relatively few individuals $>75$ years of age who were included in RCTs of high- vs. moderate-intensity statin therapy, there was no clear evidence of an additional reduction in atherosclerotic CVD events from high-intensity statin therapy [1]. Moreover, individuals $>75$ years of age did experience a reduction in CVD events in the available trials of mostly moderate-intensity statin therapy, compared with controls [1]. Therefore, taking the above into account (as well as all the risk factors of statin intolerance in this group of pa- 
M. Banach, M. Rizzo, P.P. Toth, M. Farnier, M.H. Davidson, K. Al-Rasadi, W.S. Aronow, V. Athyros, D.M. Djuric, M.V. Ezhov, R.S. Greenfield, G.K. Hovingh, K. Kostner, C. Serban, D. Lighezan, Z. Fras, P.M. Moriarty, P. Muntner, A. Goudev, R. Ceska, S.J. Nicholls, M. Broncel, D. Nikolic, D. Pella, R. Puri, J. Rysz, N.D. Wong, L. Bajnok, S.R. Jones, K.K. Ray, D.P. Mikhailidis

tients) moderate-intensity statin therapy (e.g. rosuvastatin 5-10 mg) should be considered for individuals $>75$ years of age with clinical atherosclerotic CVD according to the ACC/AHA lipid guidelines [1].

\section{Expert opinion}

Elderly patients are at a higher risk of statin intolerance.

Statin therapy should be started when clinically appropriate, especially if the benefits on CVD prevention outweigh potential risks.

The authors of this position paper recommend discontinuing statin therapy in case of severe illness, major surgery, or major trauma until the person recovers. Any such decision should be balanced with the risk of discontinuing statins.

Hydrophilic statins at moderate-intensity doses should be first considered in elderly patients with CVD.

\section{Rheumatic diseases and statin intolerance}

Statins might be generally safely administered in rheumatic diseases with concomitant CVD. Moreover, anti-inflammatory properties of statins can positively affect the course of systemic disease, such as rheumatoid arthritis and osteoporosis without an increase in any AEs $[168,169]$. In a large cross-sectional study among 5170 participants without arthritis, the unadjusted prevalence of musculoskeletal pain was significantly higher for statin users reporting pain in any region (23\% among statin users, compared with $18 \%$ among those not using statins, $p=0.02$ ) and in the lower extremities (12 vs. $8 \%, p=0.02$ ). Conversely, among 3058 participants with arthritis (mainly osteoarthritis), statin use was not associated with higher musculoskeletal pain in any region. The similar results were obtained after adjusting for potential confounders [170].

Several case/non-case studies showed that statins might have been significantly associated with an increased risk of polymyalgia rheumatica ( $n=327$ cases; reporting odds ratio (ROR) 14.21) [69], rheumatoid arthritis ( $n=508$ patients; adjusted $\mathrm{OR}=1.71, p=0.007$; a trend between the potency of statin treatment and the risk of RA was observed) [70] and lupus erythematosus $(\mathrm{OR}=1.67)[71]$. In the last study [71] cases were defined as drug-induced lupus reports. Non-cases were defined as all reports of other adverse drug reactions (ADRs). Among 235,147 ADR reports, 232 were drug-induced lupus. Exposure to statins was present in 17 (7.3\%) cases and in 10,601 (4.7\%) non-cases. Reporting odds ratio (ROR) for statin exposure associated with lupus erythematosus was 1.67 (ROR was > 1 for each statin but fluvastatin) [71]. Taking into account the small number of cases with statin therapy $(n=17)$ these results should be further confirmed in other studies. In the meta-analysis by Noel [171], the author investigated the link between statin therapy and the risk of drug-induced autoimmune reactions, including lupus erythematosus; 28 cases of statin-induced autoimmune diseases were included in the analysis (systemic lupus erythematosus was reported in 10 cases and polymyositis in 14 cases). The mean time of exposure before disease onset was $12.8 \pm 18$ months; range 1 month to 6 years. In many patients, antinuclear antibodies were still positive many months after clinical recovery. A lethal outcome has been recorded in 2 patients despite aggressive immunosuppressive therapy [171]. The authors concluded that longterm exposure to statins might be associated with drug-induced lupus erythematosus and other autoimmune disorders [171], however further studies are necessary to confirm it as well as to find an optimal way to manage these patients.

Finally, strong epidemiologic evidence demonstrates that in rheumatic disease, including rheumatoid arthritis and systemic lupus erythematosus, there is a premature, rapidly progressing atherosclerosis development, followed by CV complications [172]. Therefore, the discontinuation of statin therapy in these patients might be associated with significant increased risk of CV and all-cause mortality [173]. De Vera et al. aimed to evaluate the impact of statin discontinuation on CVD and all-cause mortality in a population-based cohort of patients with rheumatoid arthritis [173]. Statin discontinuation was defined as persistent nonuse for $\geq 3$ months during the therapy course. Over 16,144 person-years of follow-up in the cohort of 4,102 incident statin users, the authors documented 198 deaths due to CVD and 467 deaths overall. Adjusted hazard ratios for the association of statin discontinuation with death were 1.60 for CVD mortality and 1.79 for all-cause mortality. The association between statin discontinuation and mortality outcomes was not modified by timing of the first statin prescription, age and sex [173]. It can therefore be assumed that the significant benefits of statins outweigh the possible risk of systemic diseases development or side effects in patients with any rheumatic diseases taking statins.

\section{Expert opinion}

Statins should always be considered in patients with rheumatic diseases and high CVD risk.

Rheumatic diseases increase the risk of statin intolerance e.g. due to often elevated CK activity at baseline. Individualization of therapy and collaboration with the rheumatologist in the treatment process is mandatory. 


\section{Major surgery and statin intolerance}

At present, most evidence suggests that statin therapy does not increase the risk of any complications associated with cardiac and non-cardiac major surgery. In a large meta-analysis $(n=31,725)$, preoperative statin exposure significantly reduced early mortality $(O R=0.57)$, stroke $(O R=0.74)$ and atrial fibrillation $(O R=0.6)$ after cardiac surgery [174]. In other study, which included 213,347 older patients who underwent major elective surgery, statin therapy was associated with $16 \%$ lower risk of AKI and $21 \%$ lower risk of mortality [175]. In a recent single-institution study 7,777 of non-cardiac operations were analyzed [176]. Procedure type included general surgery (33.5\%), breast/endocrine (9.5\%), colorectal (19.7\%), hepatobiliary/ pancreatic $(5.1 \%)$, orthopedic $(2.6 \%)$, skin/earnose-throat $(1.9 \%)$, thoracic $(0.7 \%)$, upper gastrointestinal (8.4\%) and vascular cases (118.6\%). Preoperative statin use was present in $10.5 \%$ of total cases. The use of statins was associated with decreased major, non-cardiac complications $(\mathrm{OR}=0.62 ; p<0.001)$, respiratory complications $(\mathrm{OR}=0.63 ; p=0.017)$, venous thromboembolic events $(\mathrm{OR}=0.41 ; p=0.044)$ and infectious complications $(\mathrm{OR}=0.65 ; p=0.023)$ [176]. In a retrospective cohort study of 780,591 patients who underwent major non-cardiac surgery, the risk of postoperative mortality was considerably lower among statin users (unadjusted $O R=0.68$ ) compared with patients without statins [177]. A large meta-analysis of 15 studies $(n=223,010)$ also found that perioperative statin therapy was associated with a substantial reduction of mortality risk by $38 \%$ after cardiac surgery $(p=0.0001)$, by $59 \%$ following vascular surgery $(p=0.0001)$ and by $44 \%$ after non-cardiac surgery $(p<0.01)$ [178].

Sudden withdrawal of perioperative statins might result in adverse clinical outcomes [179]. Statin withdrawal more than 4 days after aortic surgery is associated with a 3-fold higher risk of post-operative myocardial ischemia [180]. A potential limitation of perioperative statin use is the lack of a parenteral formulation; therefore, statins with a long half-life (e.g. atorvastatin) or extended release formulations (e.g. lovastatin) should be favored in the postoperative period when oral intake is not feasible [181]. A concern relating to the use of perioperative statin therapy has been the risk of statin-induced myopathy and rhabdomyolysis. There are numerous perioperative factors that might increase the risk of statin-induced myopathy, e.g. the impairment of renal function after major surgery, myositis, liver dysfunction and multiple drugs use during anesthesia [179, 181]. Furthermore the use of analgesic drugs and post-operative pain may mask signs of myopathy [181]. It is especially important, as failure to de- tect statin-induced myopathy may then lead to the statin being continued and the subsequent development of rhabdomyolysis and acute renal failure [181]. Therefore, the monitoring of CK and ALT/ASP activity is recommended in patients taking statins perioperatively [179, 181]. However, if any serious complications develop, the statins should be immediately discontinued and appropriate treatment initiated. According to current ESC (2014) guidelines on non-cardiac surgery [181], most patients with peripheral artery disease should receive statins. If they have to undergo open vascular surgery or endovascular intervention, statins should be continued afterwards [181]. In patients not previously treated, statins should ideally be initiated at least 2 weeks before intervention for maximal plaque-stabilizing effects and continued for at least 1 month after surgery. In patients undergoing non-vascular surgery, there is no evidence to support pre-operative statin treatment if there is no other indication [181].

\section{Expert opinion}

Perioperative statin therapy significantly reduces the risk of complications after major surgery. The authors of this position paper support the ESC guidelines on non-cardiac surgery (2014).

The careful monitoring of $C K$ and ALT/ASP activity is recommended in patients taking statins perioperatively. In case of any serious statin-related complications, statin therapy should be immediately discontinued.

\section{Definition of statin intolerance}

Statin intolerance is widely defined as not being able to tolerate a registered statin dose, due to side effects such as myalgia-myopathy, myositis, or elevation of serum liver enzyme activities [182]. Statin intolerance has been also described as a clinical syndrome with the following characteristics: (1) incapacity to use statin therapy because of appearance of symptoms and/or abnormal values of biomarkers at the initiation or at dose escalation of statin therapy; (2) no presence of individual predispositions, such as drug-drug interactions, untreated hypothyroidism, febrile illness, that may contribute to statin intolerance [18]. In addition, two different clinical patterns have been identified: the complete intolerance, when a subject is intolerant to any statin at any dose, and the partial intolerance, when a subject is intolerant to some statins at some doses [18]. Further, given that there are many statins available, it has been proposed that the statin intolerance represents intolerance to the starting dose of one statin and any dose of another statin [18]. However, the oc- 
M. Banach, M. Rizzo, P.P. Toth, M. Farnier, M.H. Davidson, K. Al-Rasadi, W.S. Aronow, V. Athyros, D.M. Djuric, M.V. Ezhov, R.S. Greenfield, G.K. Hovingh, K. Kostner, C. Serban, D. Lighezan, Z. Fras, P.M. Moriarty, P. Muntner, A. Goudev, R. Ceska, S.J. Nicholls, M. Broncel, D. Nikolic, D. Pella, R. Puri, J. Rysz, N.D. Wong, L. Bajnok, S.R. Jones, K.K. Ray, D.P. Mikhailidis

currence of different, non-specific, rare, and probably idiosyncratic adverse events complicates statin intolerance diagnosis (and in the consequence the management), increasing the risk of long-term consequences of statin-related AEs [18].

Statin intolerance represents an increasing problem related to the rising number of subjects treated with statins, limiting the benefit of such therapies for subjects at high CV risk [182]. Muscle symptoms, ranging from mild myalgia to rhabdomyolysis, are major side effects and a leading cause of statin intolerance [183]; these symptoms may occur even in the absence of CK elevation (myalgia, myopathy) [20]. However, the definition of statin-associated muscle adverse effects (myopathy) varies between the different organizations such as ACC/AHA, the National Heart, Lung and Blood Institute (NHLBI), FDA, the European Medicines Agency (EMA), the National Lipid Association (NLA) (2006 and 2014), and recently the EAS $[1,10,20,182]$. All the details concerning these definitions were clearly presented in the supplemental material (Webtable 1) of the recent EAS Consensus Panel Statement on Assessment, Aetiology and Management [10].

Given that there is currently no widely accepted definition of statin intolerance, some authors endeavored to use a practical definition in their own study. Thus, Sullivan et al. [184] in the GAUSS trial with evolocumab defined statin intolerance as the inability to tolerate at least 1 statin at any dose or an increase in dose above weekly maximums of rosuvastatin $35 \mathrm{mg}$; atorvastatin $70 \mathrm{mg}$; simvastatin $140 \mathrm{mg}$; pravastatin $140 \mathrm{mg}$; lovastatin $140 \mathrm{mg}$; or fluvastatin $280 \mathrm{mg}$, because of intolerable myalgia (muscle pain, soreness, weakness, or cramps) or myopathy (myalgia plus elevated CK) and having symptom improvement or resolution with statin discontinuation. Such approach resulted in a population with an unmet medical goal, as exemplified by the mean LDL-C > $190 \mathrm{mg} / \mathrm{dl}$, $24 \%$ of subjects with atherosclerotic disease and $50 \%$ at high or moderately high CV risk and even $84 \%$ of all participants were unable to tolerate low doses of any statin [184]. The definition did not also mention that symptom improvement or resolution might often appear after reducing of statin dose, without necessity of discontinuing of statin therapy [185]. Finally it seems to be too complicated for general practitioners and family doctors, who for the most part take care of statin intolerant patients. In the GAUSS-2 trial [186] the definition was updated and simplified. Statin intolerance was defined as the inability to tolerate $\geq 2$ statins at any dose or increase the dose above the smallest tablet strength because of intolerable muscle-related side effects, which resolved or improved significantly upon dose decrease or discontinuation. The ongoing GAUSS-3 trial [187, 188] the definition was again changed, and statin intolerance was defined as the inability to tolerate atorvastatin at an average dose of $10 \mathrm{mg} /$ day and unable to tolerate any other statin at any dose due to skeletal muscle related symptoms OR the inability to tolerate at least 3 statins - one statin at the lowest starting average daily dose and any other 2 statins at any dose due to skeletal muscle related symptoms OR documented history of CK elevation > 10 times the ULN accompanied by muscle symptoms while on statin therapy, which resolved upon discontinuation AND symptoms resolved or improved when statin dose was decreased or discontinued. This definition rises at least few questions - why the authors decided to mention only atorvastatin especially statin intolerance is observed relatively often after atorvastatin [23, 24]. Another question concerns the mentioned number of statins (at least 3 - in GAUSS-2 there were at least 2 [186]). Finally, it is difficult to agree with the statement that statin intolerance should be also diagnosed based on the patient's history only, as such case of statin intolerability might happen incidentally, accompanied by the condition/situation, which essentially increase the risk of statin intolerance (e.g. physical exertion, hypothyroidism) [7, 11]. Despite that, GAUSS-3 trial might bring very important information for statin intolerant patients due to the fact that for the first time the authors decided to analyze the drug's rechallenge, since there is evidence that patients who discontinue statins due to subjective intolerance are able to tolerate this drug class upon rechallenge [7, 11, 187, 188]. In ODYSSEY ALTERNATIVE trial [189] with alirocumab statin intolerance was definition was very similar to the one used in GAUSS-2 trial: the inability to tolerate at least 2 different statins because of unexplained skeletal muscle-related symptoms, such as pain, aches, weakness, or cramping that began or increased during statin therapy and returned to baseline when statin therapy was discontinued. For each patient to meet this definition one of the statins that was discontinued had to have been at the lowest approved daily starting dose (i.e., rosuvastatin $5 \mathrm{mg}$, atorvastatin $10 \mathrm{mg}$, simvastatin $10 \mathrm{mg}$, lovastatin $20 \mathrm{mg}$, pravastatin $40 \mathrm{mg}$, fluvastatin $40 \mathrm{mg}$, pitavastatin $2 \mathrm{mg}$ ); the other statin was at any dose. Finally in June 2014 NLA Expert Panel on Statin Intolerance suggested the following definition: Statin intolerance is a clinical syndrome characterized by the inability to tolerate at least 2 statins: one statin at the lowest starting daily dose (rosuvastatin $5 \mathrm{mg}$, atorvastatin $10 \mathrm{mg}$, simvastatin $10 \mathrm{mg}$, lovastatin $20 \mathrm{mg}$, pravastatin $40 \mathrm{mg}$, fluvastatin $40 \mathrm{mg}$, and pitavastatin $2 \mathrm{mg}$ ) AND another statin at any daily dose, due to either 
objectionable symptoms (real or perceived) or abnormal lab determinations, which are temporally related to statin treatment and reversible upon statin discontinuation, but reproducible by rechallenge with other known determinants being excluded (such as hypothyroidism, interacting drugs, concurrent illnesses, significant changes in physical activity or exercise, and underlying muscle disease) [190]. While it has been a very good attempt of statin intolerance definition, it has again few limitations: (1) 'perceived symptoms' might not often be related to statin therapy, that is why it is so important to try to confirm that the observed AEs are indeed associated with statin therapy, (2) in many cases reduction of statin dose is enough to observe the symptoms resolution or improvement; and (3) the inclusion of drug's rechallenge to the definition might underestimate the risk (and number of patients) of statin intolerance, especially there is evidence that patients who discontinue statins are able to tolerate these drugs upon rechallenge [7, 11, 187, 188, 190].

In the study with mipomersen, Visser et al. [191] suggested the protocol-specified definition of statin intolerance including myalgia, liver enzyme increasing, neurological symptoms and other reasons. The subjects were considered to be statin intolerant if they were unable to tolerate at least 2 different statins due to side effects of any kind [190]. Donnelly et al. in their large observational study of statin prescribing in subjects with type 2 diabetes [192] have demonstrated that two functional variants, V174A and N130D of the SLCO1B1 gene, known to encode organic anion-transporting polypeptide (OATP)-C/OATP1B1 which regulate the hepatic uptake of statins, are associated with statin intolerance. Their definition of intolerance was derived from statin discontinuation, switching or dose reduction and may incorporate a range of side effects, but not necessarily related to myopathy or myalgia [192]. Both biochemical abnormalities and prescribing changes within individuals have been considered in defining of statin intolerance. Biochemical abnormalities included those exceeding the ULN ranges for both ALT and CK, as determined for the age and gender of each subject. Relevant prescribing changes included switching statin to equivalent or lower dose, dose reduction of the same statin, or discontinuation of statin. Statin intolerance was defined in two cases: 1) abnormal CK activity ( 1 to 3 times over the ULN) but with normal CK activity before statin therapy; or 2) abnormal ALT activity, with normal ALT activity before statin therapy, and also the cases of an increasing $\geq 50 \%$ in ALT activity from baseline was considered as abnormal [192]. If these abnormalities have been accompanied by a relevant change in prescribing such subjects were defined as intolerant. In addition, subjects with normal CK activity before a prescribing change were also defined as intolerant. On the other hand, the subjects with abnormal CK or ALT activity but without change in prescribing were defined as neither tolerant nor intolerant. The tolerant group was defined as subjects with normal CK or ALT activity during the period of statin treatment, with no prescribing changes and a consistent statin dose $(10 \mathrm{mg}$ of simvastatin or greater) [192]. Interestingly, Raju et al. pointed out that in the clinical practice statins have been associated with several adverse effects forcing abrupt discontinuation without consulting a physician and despite the confirmed safety and efficacy profile, and this is referred as statin intolerance [193]. At this point it is important to emphasize the role of nocebo effect (= side effects experienced by patients if they anticipate a medication might be harmful), as an important reason of statin discontinuation without consulting with a physician, what might overestimate the number of patients with statin intolerance [194].

As the routine tests or assays that evaluate statin intolerance or adverse effects (with the exception of muscle and liver enzyme assays) currently do not exist, there is a large need to unify the classification of statin intolerance. Several factors mentioned above (subject-related and drug-related) which determine statin intolerance should be carefully examined and observed before this clinical syndrome can be considered [195]. Before all, it should strive to reduce the risk of statin intolerance by: careful comprehensive assessment of the patient before treatment, taking into account the medical history (illness, concomitant therapy), patient counseling, informing about possible symptoms and ongoing monitoring [18]. Baseline liver function tests should be obtained before initiating statin therapy and CK activity as well in all subjects at increased risk of myotoxicity. Hypothyroidism and other predisposing conditions should be excluded in patients who develop myalgia [196]. The history of statin intolerance should be also taken into account. Such subjects may be able to tolerate lower dose or another statin. Further, the role of exercise testing combined with imaging might eventually have a clinical role $[196,197]$.

The correct prevalence of statin intolerance is questionable given that many studies have depended on self-reporting of muscle side-effects without expert assessment [197]. We suggest that statin intolerance should not be considered immediately with occurrence of muscle symptoms particularly as well as abnormal biomarker values. Detailed examination of biochemical parameters should be performed and repeated with careful survey of etiologies of the occurred symptoms. When all other 
M. Banach, M. Rizzo, P.P. Toth, M. Farnier, M.H. Davidson, K. Al-Rasadi, W.S. Aronow, V. Athyros, D.M. Djuric, M.V. Ezhov, R.S. Greenfield, G.K. Hovingh, K. Kostner, C. Serban, D. Lighezan, Z. Fras, P.M. Moriarty, P. Muntner, A. Goudev, R. Ceska, S.J. Nicholls, M. Broncel, D. Nikolic, D. Pella, R. Puri, J. Rysz, N.D. Wong, L. Bajnok, S.R. Jones, K.K. Ray, D.P. Mikhailidis

etiologies are excluded (patient and drug-related) abnormal values confirmed, the next step should be change of statin dose (no more often than every $2-4$ weeks) or replacement by another statin (at suitable dose taking into account CV risk), at the time when the subject becomes asymptomatic. Which statin to use will dependent on each individual situation. If after treatments with several statins, at different doses, the muscle symptoms (and/or other mentioned above side effects) are still intolerable and/or abnormal values of biomarkers ( $>10$-fold increased in CK, together with increases in serum creatinine) remain, the subject can be characterized as intolerant to statin.

The aim of the present position paper was to suggest a unified statin intolerance definition, which should meet two main conditions: (1) to be commonly used by the physicians of all specialties who manage dyslipidemic patients, and, (2) to allow optimal diagnosis and avoid both over- and underrepresentation. Finally, we would like to focus particular attention on the patients' education in order to minimize the risk of a nocebo effect.

In brief, statin intolerance should generally involve: development of symptoms while on a statin, resolution of symptoms when the statin is discontinued, and recurrence of symptoms when the same or a different statin is restarted. Using more detailed criteria, statin intolerance is a clinical syndrome that is: (1) characterized by inability to use statins for long-term reduction of lipids and/ or cardiovascular risk because of significant symptoms and/or biomarker abnormalities that can be temporally attributed to the initiation or dose escalation of statins; if appropriate, drug withdrawal and rechallenge can strengthen the association, (2) either "complete" (intolerant to any statin at any dose) or "partial" (intolerant to some statins at some doses), and, (3) not attributable to established predispositions such as drug-drug interactions, and untreated hypothyroidism, etc.

\section{Unified definition of statin intolerance:}

1) the inability to tolerate at least 2 different statins - one statin at the lowest starting average daily dose and the other statin at any dose,

2) intolerance associated with confirmed, intolerable statin-related adverse effect(s) or significant biomarker abnormalities*,

3) symptom or biomarker changes resolution or significant improvement upon dose decrease or discontinuation,

4) symptoms or biomarker changes not attributable to established predispositions such as drug-drug interactions and recognized conditions increasing the risk of statin intolerance.

${ }^{*}$ According to the recent recommendations [10, 20, 198].

\section{The most common diagnostic errors}

There is certainly an inherent reluctance among the population in general to be placed on prescription medication. Many factors come into play such as cost, potential side effects, and the stigma of having to take medication over an indefinite period $[199,200]$. Fueling the so-called statin rebellion is the unfiltered information on the internet, interpretation of TV advertisements, and exhaustive small print package inserts warning of every conceivable side effect. It is no wonder that many patients claim statin intolerance (nocebo effect). Thus, it becomes a daunting task to appropriately diagnose and manage the myriad of symptoms that are either true statin intolerance or only perceived as such and avoiding errors in their diagnosis.

The most worrisome error in the diagnosis of statin intolerance involving muscle symptoms is not diagnosing the condition when it truly occurs. Errors in the diagnosis are not unusual because the symptom complex of muscle pain, fatigue, and nocturnal cramping are common. Statin-induced myopathy affects large muscle groups and is usually bilateral, symmetrical and may be worsened by exercise [20]. Joint pain, often mistaken for myalgia is a very unusual side effect of statin use and another etiology should be sought [168-170]. Muscle symptoms that appear only after a few days is more unusual for statin-related symptoms as true statin-related symptoms most commonly appear weeks to months after initiation of therapy or increase in dose (75\% in the first 12 weeks) and are more common in patients on high dose therapy and/or who are also taking other medication [19]. Muscle symptoms that begin after years of statin usage without a medication change are less likely to be statin-related [200]. A useful approach is to fulfill a modification of so-called Koch's Postulates [24], and remove the statin for 2-3(4) weeks. Should symptoms subside, re-challenge with the same or lower dose of statin. Should the symptoms return strong presumptive evidence exists that the symptoms are truly statin-related. Although it has been reported that statin-related symptoms can be present for months after the drug is discontinued, this is unusual and suggests that an underlying independent muscle disorder should be excluded [24, 199, 200].

Lastly, the health care providers may initiate errors in the diagnosis of statin intolerance. This may occur unintentionally as physicians create an adverse expectation, when we dutifully point out the potential side effects when initiating statin therapy [201]. In turn, patients formulate expectations regarding symptoms. Moreover, as clinicians with busy schedules, clearly it is difficult to examine the many psychosocial barriers present in some patients that can be predisposing factors for 
their statin intolerance. Errors in the diagnosis of statin intolerance are often made by accepting the diagnosis based a false patient assumption based on their history. It is interesting to note that in a recently reported survey, $14 \%$ of all patients either had no idea why they stopped their statin or reported symptoms categorized as other [202]. The Understanding Statin Use in America and Gaps in Patient Education (USAGE) survey attempted to understand the use of statins in US and gaps in patient education, and suggested that improved physician-patient communication about the side effects and benefits of statins are necessary to improve both adherence and outcomes [199]. In this way, errors in diagnosis can be essentially reduced.

\section{Conflict of interest}

$[\mathrm{MB}]$ has given lectures, received honoraria or research support, and participated in conferences, advisory boards and clinical trials sponsored by Abbott, Amgen, Daiichi-Sankyo, MSD, and Sanofi-Regeneron; [MR] - AstraZeneca, Boehringer Ingelheim, Bristol Myers Squibb, Bromatech, Chiesi Farmaceutici, Kowa, MSD Merck Sharp \& Dohme, Novartis, Novo Nordisk, Rikrea and Servier; [PPT] - Amarin, Amgen, AstraZeneca, Genzyme, GSK, Kowa, Merck, Novartis, Regeneron; [MF] - Abbott, Amgen, AstraZeneca, Eli Lilly, Genzyme, Kowa, Merck, Novartis, Pfizer, Recordati, Roche and Sanofi-Regeneron; [RSG] - Aegerion, Merck, and Sanofi-Regeneron; [KGH] - Amgen, AstraZeneca, Pfizer, Roche, and Sanofi; [PMM] - Amgen, AstraZeneca, B. Braun Medical, Inc., Genzyme, Kaneka Pharma America LLC, and Sanofi-Regeneron; [PM] - Amgen; [SJN] - Amgen, Anthera, AstraZeneca, Atheronova, Boehringer Ingelheim, Cerenis, CSL Behring, Kowa, Merck, Novartis, Omthera, Pfizer, Resverlogix, Roche, Sanofi-Regeneron, Takeda, and The Medicines Company; [MBr] - Amgen, Eli-Lilly, MSD, Pfizer, and Sanofi-Regeneron; [LB] - AstraZeneca, Amgen, Krka, and MSD; [KKR] - Abbott, Aegerion, Amgen, AstraZeneca, Cerenis, Eli Lilly, Kowa, MSD, Pfizer, Resverlogix, Roche, and Sanofi-Regeneron; [DPM] - AstraZeneca, Genzyme, and MSD. The remaining authors have nothing to disclose.

\section{References}

1. Stone NJ, Robinson J, Lichtenstein AH, et al. 2013 ACC/ AHA Guideline on the treatment of Blood Cholesterol to Reduce Atherosclerotic Cardiovascular Risk in Adults: a report of the American College of Cardiology/American Heart Association Task Force on Practice Guidelines. Circulation 2014; 129 (25 Suppl 2): S1-45.

2. Banach M, Mikhailidis DP, Kjeldsen SE, Rysz J. Time for new indications for statins? Med Sci Monit 2009; 15: MS1-5.

3. Baigent C, Keech A, Kearney PM, et al. Efficacy and safety of cholesterol-lowering treatment: prospective meta- analysis of data from 90,056 participants in 14 randomised trials of statins. Lancet 2005; 366: 1267-78.

4. Banach M, Mikhailidis DP. Statin therapy and new-onset diabetes: an attempt at recommendations. Exp Rev Endocrinol Metabol 2013; 8: 213-6.

5. Kavousi M, Leening MJ, Nanchen D, et al. Comparison of application of the ACC/AHA guidelines, Adult Treatment Panel III guidelines, and European Society of Cardiology guidelines for cardiovascular disease prevention in a European cohort. JAMA 2014; 311: 1416-23.

6. Colantonio LD, Baber U, Banach M, et al. Contrasting Cholesterol Management Guidelines for Adults with CKD. J Am Soc Nephrol 2014 Nov 13. pii: ASN.2014040400 [Epub ahead of print].

7. Thompson PD, Clarkson P, Karas RH. Statin-associated myopathy. JAMA 2003; 289: 1681-90.

8. Michalska-Kasiczak M, Sahebkar A, Mikhailidis DP, et al.; Lipid and Blood Pressure Meta-analysis Collaboration (LBPMC) Group. Analysis of vitamin D levels in patients with and without statin-associated myalgia - a systematic review and meta-analysis of 7 studies with 2420 patients. Int J Cardiol 2015; 178: 111-6.

9. Banach M, Serban C, Sahebkar A, et al.; Lipid and Blood Pressure Meta-analysis Collaboration Group. Effects of coenzyme Q10 on statin-induced myopathy: a meta-analysis of randomized controlled trials. Mayo Clin Proc 2015; 90: 24-34.

10. Stroes ES, Thompson PD, Corsini A, et al.; European Atherosclerosis Society Consensus Panel. Statin-associated muscle symptoms: impact on statin therapy-European Atherosclerosis Society Consensus Panel Statement on Assessment, Aetiology and Management. Eur Heart J 2015 Feb 18. pii: ehv043 [Epub ahead of print].

11. Joy TR, Hegele RA. Narrative review: statin-related myopathy. Ann Intern Med 2009; 150: 858-68.

12. Grundy SM. Can statins cause chronic low-grade myopathy? Ann Intern Med 2002; 137: 617-8.

13. Bays H. Statin safety: an overview and assessment of the data-2005. Am J Cardiol 2006; 97: 6C-26C.

14. Bitzur R, Cohen H, Kamari Y, Harats D. Intolerance to statins: mechanisms and management. Diabetes Care 2013; 36: S325-30.

15. Marciante KD, Durda JP, Heckbert SR, et al. Cerivastatin, genetic variants, and the risk of rhabdomyolysis. Pharmacogenet Genomics 2011; 21: 280-8.

16. McClure DL, Valuck RJ, Glanz M, Hokanson JE. Systematic review and meta-analysis of clinically relevant adverse events from HMG CoA reductase inhibitor trials worldwide from 1982 to present. Pharmacoepidemiol Drug Saf 2007; 16: 132-43.

17. Banach M, Serban C, Aronow WS, et al. Lipid, blood pressure and kidney update 2013. Int Urol Nephrol 2014; 46: 947-61.

18. Mancini GB, Tashakkor AY, Baker S, et al. Diagnosis, prevention, and management of statin adverse effects and intolerance: Canadian Working Group Consensus update. Can J Cardiol 2013; 29: 1553-68.

19. Jacobson TA. Toward "pain-free" statin prescribing: clinical algorithm for diagnosis and management of myalgia. Mayo Clin Proc 2008; 83: 687-700.

20. Rosenson RS, Baker SK, Jacobson TA, Kopecky SL, Parker BA. An assessment by the statin muscle safety task force: 2014 update. J Clin Lipidol 2014; 8: S58-71.

21. Reiner Z. Resistance and intolerance to statins. Nutr Metab Cardiovasc Dis 2014; 24: 1057-66. 
M. Banach, M. Rizzo, P.P. Toth, M. Farnier, M.H. Davidson, K. Al-Rasadi, W.S. Aronow, V. Athyros, D.M. Djuric, M.V. Ezhov, R.S. Greenfield, G.K. Hovingh, K. Kostner, C. Serban, D. Lighezan, Z. Fras, P.M. Moriarty, P. Muntner, A. Goudev, R. Ceska, S.J. Nicholls, M. Broncel, D. Nikolic, D. Pella, R. Puri, J. Rysz, N.D. Wong, L. Bajnok, S.R. Jones, K.K. Ray, D.P. Mikhailidis

22. Stephen K. Galson Acting Director U.S. Food and Drug Administration Center for Drug Evaluation and Research. FDA Rejection of Citizen Petition. Letter dated 11 March 2005, Food and Drug Administration Docket No. 2004P-0113/CP1.

23. Bruckert E, Hayem G, Dejager S, Yau C, Bégaud B. Mild to moderate muscular symptoms with high-dosage statin therapy in hyperlipidemic patients: the PRIMO study. Cardiovasc Drugs Ther 2005; 19: 403-14.

24. Parker BA, Capizzi JA, Grimaldi AS, et al. Effect of statins on skeletal muscle function. Circulation 2013; 127: 96-103.

25. Study of the Effectiveness of Additional Reductions in Cholesterol and Homocysteine (SEARCH) Collaborative Group; Armitage J, Bowman L, Wallendszus K, et al. Intensive lowering of LDL cholesterol with $80 \mathrm{mg}$ versus $20 \mathrm{mg}$ simvastatin daily in 12,064 survivors of myocardial infarction: a double-blind randomised trial. Lancet 2010; 376: 1658-69.

26. HPS2-THRIVE Collaborative Group. HPS2-THRIVE randomized placebo-controlled trial in 25673 highrisk patients of ER niacin/laropiprant: trial design, pre-specified muscle and liver outcomes, and reasons for stopping study treatment. Eur Heart J 2013; 34 1279-91.

27. Reiner Z, Catapano AL, De Backer G, et al. ESC/EAS guidelines for the management of dyslipidaemias: the Task Force for the management of dyslipidaemias of the European Society of Cardiology (ESC) and the European Atherosclerosis Society (EAS). Eur Heart J 2011; 32: $1769-818$

28. Björnsson E, Jacobsen El, Kalaitzakis E. Hepatotoxicity associated with statins: reports of idiosyncratic liver injury post-marketing. J Hepatol 2012; 56: 374-80.

29. Bergmann OM, Kristjansson G, Jonasson JG, Björnsson ES. Jaundice due to suspected statin hepatotoxicity: a case series. Dig Dis Sci 2012; 57: 1959-64.

30. Marcum ZA, Vande Griend JP, Linnebur SA. FDA drug safety communications: a narrative review and clinical considerations for older adults. Am J Geriatr Pharmacother 2012; 10: 264-71.

31. FDA Drug Safety Communication: Important safety label changes to cholesterol-lowering statin drugs (2-28-2012). http://www.fda.gov/Drugs/DrugSafety/ ucm293101.htm

32. Katsiki N, Banach M. Statin use and risk of diabetes mellitus in postmenopausal women. Clin Lipidol 2012 7: 267-70.

33. Barylski M, Małyszko J, Rysz J, Myśliwiec M, Banach $M$. Lipids, blood pressure, kidney - what was new in 2011? Arch Med Sci 2011; 7: 1055-66.

34. Banach M, Malodobra-Mazur M, Gluba A, Katsiki N Rysz J, Dobrzyn A. Statin therapy and new-onset diabetes: molecular mechanisms and clinical relevance. Curr Pharm Des 2013; 19: 4904-12.

35. Barylski M, Nikolic D, Banach M, Toth PP, Montalto G, Rizzo M. Statins and new-onset diabetes. Curr Pharm Des 2014; 20: 3657-64.

36. Sattar N, Preiss D, Murray HM, et al. Statins and risk of incident diabetes: a collaborative meta-analysis of randomized statin trials. Lancet 2010; 375: 735-42.

37. Rajpathak SN, Kumbhani DJ, Crandall J, Barzilai N, Alderman M, Ridker PM. Statin therapy and risk of developing type 2 diabetes: a meta-analysis. Diabetes Care 2009; 32: 1924-9.

38. Preiss D, Seshasai SR, Welsh P, et al. Risk of incident diabetes with intensive-dose compared with moder- ate-dose statin therapy: a meta-analysis. JAMA 2011; 305: 2556-64.

39. Ridker PM, Pradhan A, MacFadyen JG, Libby P, Glynn RJ. Cardiovascular benefits and diabetes risks of statin therapy in primary prevention: an analysis from the JUPITER trial. Lancet 2012; 380: 565-71.

40. Sugiyama T, Tsugawa Y, Tseng CH, Kobayashi Y, Shapiro MF. Different time trends of caloric and fat intake between statin users and nonusers among US adults: gluttony in the time of statins? JAMA Intern Med 2014; 174: 1038-45.

41. Golomb BA, Evans MA. Statin adverse effects: a review of the literature and evidence for a mitochondrial mechanism. Am J Cardiovasc Drugs 2008; 8: 373-418.

42. Fernández AB, Karas RH, Alsheikh-Ali AA, Thompson PD. Statins and interstitial lung disease: a systematic review of the literature and of food and drug administration adverse event reports. Chest 2008; 134: 824-30.

43. Vandiver W, Hunter ML. Statin adverse effects: sorting out the evidence. Fam Pract 2013; 62: 730.

44. Zureik M, Courbon D, Ducimetiere P. Serum cholesterol concentration and death from suicide in men: Paris prospective study I. BMJ 1996; 313: 649-51.

45. Olson MB, Kelsey SF, Matthews KA, et al. Lipid-lowering medication use and aggression scores in women: a report from the NHLBI-sponsored WISE study. J Women's Health 2008; 17: 187-94.

46. Kang JH, Kao LT, Lin HC, Tsai MC, Chung SD. Statin use increases the risk of depressive disorder in stroke patients: a population-based study. J Neurolog Sci 2015; 348: 89-93.

47. Amarenco P, Bogousslavsky J, Callahan A; Investigators SPbARiCL. High-dose atorvastatin after stroke or tran sient ischemic attack. N Engl J Med 2006; 355: 549-59.

48. Golomb BA, Kane T, Dimsdale JE. Severe irritability associated with statin cholesterol-lowering drugs. QJM 2004; 97: 229-35

49. Tuccori M, Lapi F, Testi A, et al. Statin-associated psychiatric adverse events. Drug Saf 2008; 31: 1115-23.

50. Boriani G, Biffi M, Strocchi E, Branzi A. Nightmares and sleep disturbances with simvastatin and metoprolol. Ann Pharmacother 2001; 35: 1292.

51. Carter AA, Gomes T, Camacho X, Juurlink DN, Shah BR, Mamdani MM. Risk of incident diabetes among patients treated with statins: population based study. BMJ 2013; 346: f2610.

52. Segal AS. Alopecia associated with atorvastatin. Am J Med 2002; 113: 171.

53. Pua VS, Scolyer RA, Barnetson RS. Pravastatin-induced lichenoid drug eruption. Australas J Dermatol 2006; 47: 57-9.

54. Adcock B, Hornsby L, Jenkins K. Dermographism: an adverse effect of atorvastatin. J Am Board Fam Pract 2001; 14: 148-51.

55. Anliker M, Wüthrich B. Chronic urticaria to atorvastatin. Allergy 2002; 57: 366.

56. Pfeiffer CM, Kazenoff S, Rothberg HD. Toxic epidermal necrolysis from atorvastatin. JAMA 1998; 279: 1613-4.

57. Krasovec M, Elsner P, Burg G. Generalized eczematous skin rash possibly due to HMG-CoA reductase inhibitors. Dermatology 1993; 186: 248-52.

58. Leuschen J, Mortensen EM, Frei CR, Mansi EA, Panday V, Mansi I. Association of statin use with cataracts: a propensity score-matched analysis. JAMA Ophthalmol 2013; 131: 1427-34.

59. Fraunfelder F, Richards AB. Diplopia, blepharoptosis, and ophthalmoplegia and 3-hydroxy-3-methyl-glu- 
taryl-CoA reductase inhibitor use. Ophthalmology 2008; 115: 2282-5.

60. Athyros VG, Elisaf M, Papageorgiou AA, et al. Effect of statins versus untreated dyslipidemia on serum uric acid levels in patients with coronary heart disease: a subgroup analysis of the GREek Atorvastatin and Coronary-heart-disease Evaluation (GREACE) study. Am J Kidney Dis 2004; 43: 589-99.

61. Hippisley-Cox J, Coupland C. Unintended effects of statins in men and women in England and Wales: population based cohort study using the QResearch database. BMJ 2010; 340: c2197.

62. Kostis JB, Dobrzynski JM. The effect of statins on erectile dysfunction: a meta-analysis of randomized trials. J Sex Med 2014; 11: 1626-35.

63. De Graaf L, Brouwers A, Diemont W. Is decreased libido associated with the use of HMG-CoA-reductase inhibitors? Br J Clin Pharmacol 2004; 58: 326-8.

64. Roberto G, Biagi C, Montanaro N, Koci A, Moretti U, Motola D. Statin-associated gynecomastia: evidence coming from the Italian spontaneous ADR reporting database and literature. Eur J Clin Pharmacol 2012; 68: 1007-11.

65. Schooling CM, Au Yeung SL, Freeman G, Cowling BJ. The effect of statins on testosterone in men and women, a systematic review and meta-analysis of randomized controlled trials. BMC Med 2013; 11: 57.

66. Groneberg DA, Barkhuizen A, Jeha T. Simvastatin-induced thrombocytopenia. Am J Hematol 2001; 67: 277.

67. McCarthy LJ, Porcu P, Fausel CA, Sweeney CJ, Danielson CF. Thrombotic thrombocytopenic purpura and simvastatin. Lancet 1998; 352: 1284-5.

68. McCarthy LJ, Dlott JS, Orazi A, Waxman D, Miraglia CC, Danielson CF. Thrombotic thrombocytopenic purpura: yesterday, today, tomorrow. Ther Apher Dial 2004; 8: 80-6.

69. de Jong HJ, Saldi SR, Klungel OH, et al. Statin-associated polymyalgia rheumatica. An analysis using WHO global individual case safety database: a case/noncase approach. PLoS One 2012; 7: e41289.

70. de Jong $\mathrm{HJ}$, Klungel $\mathrm{OH}$, van Dijk L, et al. Use of statins is associated with an increased risk of rheumatoid arthritis. Ann Rheum Dis 2012; 71: 648-54.

71. Moulis G, Bene J, Sommet A, Sailler L, Lapeyre-Mestre $\mathrm{M}$, Montastruc JL; French Association of PharmacoVigilance Centres. Statin-induced lupus: a case/ noncase study in a nationwide pharmacovigilance database. Lupus 2012; 21: 885-9.

72. Lim S, Despres JP, Koh KK. Prevention of atherosclerosis in overweight/obese patients-in need of novel multi-targeted approaches. Circ J 2011; 75: 1019-27.

73. Monda KL, Ballantyne CM, North KE. Longitudinal impact of physical activity on lipid profiles in middle-aged adults: the Atherosclerosis Risk in Communities Study. J Lipid Res 2009; 50: 1685-91.

74. Kearns AK, Bilbie CL, Clarkson PM, et al. The creatine kinase response to eccentric exercise with atorvastatin $10 \mathrm{mg}$ or $80 \mathrm{mg}$. Atherosclerosis 2008; 200: 121-5.

75. Meador BM, Huey KA. Statin-associated myopathy and its exacerbation with exercise. Muscle Nerve 2010; 42: 469-79.

76. Sinzinger $\mathrm{H}, \mathrm{O}$ 'Grady J. Professional athletes suffering from familial hypercholesterolaemia rarely tolerate statin treatment because of muscular problems. $\mathrm{Br}$ J Clin Pharmacol 2004; 57: 525-8.

77. Parker BA, Augeri AL, Capizzi JA, et al. Effect of statins on creatine kinase levels before and after a marathon run. Am J Cardiol 2012; 109: 282-7.
78. Thompson PD, Zmuda JM, Domalik LJ, Zimet RJ, Staggers J, Guyton JR. Lovastatin increases exercise-induced skeletal muscle injury. Metabolism 1997; 46: 1206-10.

79. Kokkinos PF, Faselis C, Myers J, Panagiotakos D, Doumas $M$. Interactive effects of fitness and statin treatment on mortality risk in veterans with dyslipidaemia: a cohort study. Lancet 2013; 381: 394-9.

80. Westwood FR, Bigley A, Randall K, Marsden AM, Scott RC. Statin-induced muscle necrosis in the rat: distribution, development, and fibre selectivity. Toxicol Pathol 2005; 33: 246-57.

81. Kwak HB, Thalacker-Mercer A, Anderson EJ, et al. Simvastatin impairs ADP-stimulated respiration and increases mitochondrial oxidative stress in primary human skeletal myotubes. Free Radic Biol Med 2012; 52: 198-207.

82. Sirvent P, Fabre O, Bordenave S, et al. Muscle mitochondrial metabolism and calcium signaling impairment in patients treated with statins. Toxicol Appl Pharmacol 2012; 259: 263-8.

83. Urso ML, Clarkson PM, Hittel D, Hoffman EP, Thompson PD. Changes in ubiquitin proteasome pathway gene expression in skeletal muscle with exercise and statins. Arterioscler Thromb Vasc Biol 2005; 25: 2560-6.

84. Huh JY, Mougios V, Kabasakalis A, et al. Exercise-induced irisin secretion is independent of age or fitness level and increased irisin may directly modulate muscle metabolism through AMPK activation. I Clin Endocrinol Metabol 2014; 99: E2154-61.

85. Thompson PD, Parker B. Statins, Exercise, and exercise training. J Amn Coll Cardiol 2013; 62: 715-6.

86. Tziomalos K, Athyros VG, Mikhailidis DP. Statin discontinuation: an underestimated risk? Curr Med Res Opin 2008; 24: 3059-62.

87. Sirvent P, Mercier J, Lacampagne A. New insights into mechanisms of statin-associated myotoxicity. Curr Opin Pharmacol 2008; 8: 333-8.

88. Graham DJ, Staffa JA, Shatin D, et al. Incidence of hospitalized rhabdomyolysis in patients treated with lipid-lowering drugs. JAMA 2004; 292: 2585-90.

89. Sirvent $\mathrm{P}$, Fabre $\mathrm{O}$, Bordenave $\mathrm{S}$, et al. Muscle mitochondrial metabolism and calcium signaling impairment in patients treated with statins. Toxicol Appl Pharmacol 2012; 259: 263-8.

90. Gaitonde DY, Rowley KD, Sweeney LB. Hypothyroidism: an update. Am Fam Physician 2012; 86: 244-51.

91. Arruda AP, Ketzer LA, Nigro M, Galina A, Carvalho DP, de Meis L. Cold tolerance in hypothyroid rabbits: role of skeletal muscle mitochondria and sarcoplasmic reticulum Ca2+ ATPase isoform 1 heat production. Endocrinology 2008; 149: 6262-71.

92. Farias Moeller R, Zecavati N, Sherafat-Kazemzadeh R, Aleinikoff S, Rennert W. Adolescent with rhabdomyolysis due to undiagnosed hypothyroidism. Case Rep Pediatr 2011; 2011: 670673.

93. Lando HM, Burman KD. Two cases of statin-induced myopathy caused by induced hypothyroidism. Endocr Pract 2008; 14: 726-31.

94. Kiernan TJ, Rochford M, McDermott JH. Simvastatin induced rhabdomyolysis and an important clinical link with hypothyroidism. Int J Cardiol 2007; 119: 374-6.

95. Antons KA, Williams CD, Baker SK, Phillips PS. Clinical perspectives of statin-induced rhabdomyolysis. Am J Med 2006; 119: 400-9. 
M. Banach, M. Rizzo, P.P. Toth, M. Farnier, M.H. Davidson, K. Al-Rasadi, W.S. Aronow, V. Athyros, D.M. Djuric, M.V. Ezhov, R.S. Greenfield, G.K. Hovingh, K. Kostner, C. Serban, D. Lighezan, Z. Fras, P.M. Moriarty, P. Muntner, A. Goudev, R. Ceska, S.J. Nicholls, M. Broncel,

96. Bar SL, Holmes DT, Frohlich J. Asymptomatic hypothy roidism and statin-induced myopathy. Can Fam Physician 2007; 53: 428-31.

97. Al-Salameh A, Bihan H, Keller-Petrot I, Reach G, Dhote R, Cohen R. Statins should be used with greater caution in patients undergoing thyroid hormone withdrawal for radioactive iodine treatment. Thyroid 2011; 21 : 457-8.

98. Garber JR, Cobin RH, Gharib H, et al.; for the American Association of Clinical Endocrinologists and the American Thyroid Association Taskforce on Hypothyroidism in Adults. Clinical Practice Guidelines for Hypothyroidism in Adults. Thyroid 2012; 22: 1200-35.

99. Rando LP, Cording SA, Newnham HH. Successful reintroduction of statin therapy after myositis: was there another cause? Med J Aust 2004; 180: 472-3.

100. Lioudaki E, Mavroeidi NG, Mikhailidis DP, Ganotakis ES Subclinical hypothyroidism and vascular risk: an update. Hormones (Athens) 2013; 12: 495-506.

101. Duman D, Sahin S, Esertas K, Demirtunc R. Simvastatin improves endothelial function in patents with subclin ical hypothyroidism. Heart Vessels 2007; 22: 88-93.

102. Requena Carrión E, Ayala Jiménez L, Sierra García F. Renal failure due to simvastatin-induced rhabdomyolysis in a patient with subclinical hypothyroidism. Farm Hosp 2010; 34: 45-6.

103. Bryson $\mathrm{CL}, \mathrm{Au} \mathrm{DH}$, Sun $\mathrm{H}$, Williams EC, Kivlahan DR, Bradley KA. Alcohol screening scores and medication nonadherence. Ann Intern Med 2008; 149: 795-804.

104. Smit JW, Wijnne HJ, Schobben F, Sitsen A, de Bruin TW, Erkelens W. Effects of alcohol and fluvastatin on lipid metabolism and hepatic function. Ann Int Med 1995; 122: 678-80.

105. Mukamal KJ, Smith CC, Karlamangla AS, Moore AA Moderate alcohol consumption and safety of lovastatin and warfarin among men: the post-coronary artery bypass graft trial. Am J Med 2006; 119: 434-40.

106. Smit JW, Wijnne HJ, Schobben F, Sitsen A, de Bruin TW, Erkelens W. Effects of alcohol and fluvastatin on lipid metabolism and hepatic function. Ann Int Med 1995 122: 678-80.

107. Hayashi S, Watanabe J, Kawajiri K. Genetic polymorphisms in the 5'-flanking region change transcriptional regulation of the human cytochrome P450IIE1 gene. J Biochem 1991; 110: 559-65.

108. Fifth Joint Task Force of the European Society of Cardiology; European Association of Echocardiography; European Association of Percutaneous Cardiovascular Interventions; European Heart Rhythm Association; Heart Failure Association; European Association for Cardiovascular Prevention \& Rehabilitation; European Atherosclerosis Society; International Society of Behavioura Medicine; European Stroke Organisation; European Society of Hypertension; European Association for the Study of Diabetes; European Society of General Practice/Family Medicine; International Diabetes Federation Europe; European Heart Network. European Guidelines on cardiovascular disease prevention in clinical practice (version 2012): the Fifth Joint Task Force of the European Society of Cardiology and Other Societies on Cardiovascular Disease Prevention in Clinical Practice (constituted by representatives of nine societies and by invited experts). Eur J Prev Cardiol 2012; 19: 585-667.

109. Cohen DE, Anania FA, Chalasani N; National Lipid Association Statin Safety Task Force Liver Expert Panel. An assessment of statin safety by hepatologists. Am J Cardiol 2006; 97: 77C-81C.
110. Thompson PD, Clarkson PM, Rosenson RS. An assessment of statin safety by muscle experts. Am J Cardiol 2006; 97: S69-76.

111. Mofrad P, Contos MJ, Haque M, et al. Clinical and his tologic spectrum of nonalcoholic fatty liver disease associated with normal ALT values. Hepatology 2003; 37: 1286-92.

112. Athyros VG, Katsiki N, Tziomalos K, et al.; GREACE Study Collaborative Group. Statins and cardiovascular outcomes in elderly and younger patients with coronary artery disease: a post hoc analysis of the GREACE study. Arch Med Sci 2013; 9: 418-26.

113. Bader T. Liver tests are irrelevant when prescribing statins. Lancet 2010; 376: 1882-3.

114. Russo MW, Jacobson IM. How to use statins in patients with chronic liver disease. Cleve Clin J Med 2004; 71: 58-62

115. Tolman KG. The liver and lovastatin. Am J Cardiol 2002; 89: 1374-80.

116. Lai SW, Liao KF, Lai HC, Muo CH, Sung FC, Chen PC. Statin use and risk of hepatocellular carcinoma. Eur J Epidemiol 2013; 28: 485-92.

117. Hepatitis C. WHO Fact sheet $\mathrm{N}^{\circ} 164$; http://www.who. int/mediacentre/factsheets/fs164/en/.

118. Wang C, Gale M Jr, Keller BC, et al. Identification of FBL2 as a geranyl geranylated cellular protein required for hepatitis C virus RNA replication. Mol Cell 2005; 18: 425-34.

119. Ali N, Allam H, Bader T, et al. Fluvastatin interferes with hepatitis $C$ virus replication via microtubule bundling and a doublecortin-like kinase-mediated mechanism. PLoS One 2013; 8: e80304.

120. Ikeda M, Kato N. Life style-related diseases of the digestive system: cell culture system for the screening of anti-hepatitis C virus (HCV) reagents: suppression of $\mathrm{HCV}$ replication by statins and synergistic action with interferon. J Pharmacol Sci 2007; 105: 145-50.

121. Delang L, Paeshuyse J, Vliegen I, et al. Statins potentiate the in vitro anti-hepatitis C virus activity of selective hepatitis $C$ virus inhibitors and delay or prevent resistance development. Hepatology 2009; 50: 6-16.

122. Singh S, Singh PP, Singh AG, Murad MH, Sanchez W. Statins are associated with a reduced risk of hepatocellular cancer: a systematic review and meta-analysis. Gastroenterology 2013; 144: 323-32.

123. Pradelli D, Soranna D, Scotti L, et al. Statins and primary liver cancer: a meta-analysis of observational studies. Eur J Cancer Prev 2013; 22: 229-34

124. Cholesterol Treatment Trialists' (CTT) Collaboration. Efficacy and safety of more intensive lowering of LDL cholesterol: a meta-analysis of data from 170000 participants in 26 randomised trials. Lancet 2010; 376 1670-81

125. Stepien M, Banach M, Mikhailidis DP, Gluba A, Kjeldsen SE, Rysz J. Role and significance of statins in the treatment of hypertensive patients. Curr Med Res Opin 2009; 25: 1995-2005.

126. Bader T. Yes! Statins can be given to liver patients. J Hepatol 2012; 56: 305-7.

127. Bradley SM, Soine LA, Caldwell JH, Goldberg SL. Screening stress myocardial perfusion imaging and eligibility for liver transplantation. Am J Cardiol 2010; 105: 1010-3.

128. Balmer ML, Dufour JF. Treatment of hypercholesterolemia in patients with primary biliary cirrhosis might be more beneficial than indicated. Swiss Med Wkly 2008; 138: 415-9.

129. Stojakovic T, Claudel T, Putz-Bankuti C, et al. Low-dose atorvastatin improves dyslipidemia and vascular func- 
tion in patients with primary biliary cirrhosis after one year of treatment. Atherosclerosis 2010; 209: 178-83.

130. Cash WJ, O'Neill S, O’Donnell ME, et al. Randomized controlled trial assessing the effect of simvastatin in primary biliary cirrhosis. Liver Int 2013; 33: 1166-74.

131. Abu Rajab M, Kaplan MM. Statins in primary biliary cirrhosis: are they safe? Dig Dis Sci 2010; 55: 2086-8.

132. Adiels $M$, Taskinen MR, Boren J. Fatty liver, insulin resistance, and dyslipidemia. Curr Diab Rep 2008; 8: 60-4.

133. Athyros VG, Katsiki N, Karagiannis A, Mikhailidis DP. Are statins 'IDEAL' for non-alcoholic fatty liver disease? Curr Med Res Opin 2014; 30: 229-31.

134. Musso G, Gambino R, Cassader M, Pagano G. A meta-analysis of randomized trials for the treatment of nonalcoholic fatty liver disease. Hepatology 2010; 52: 79-104.

135. Athyros VG, Tziomalos K, Gossios TD, et al; GREACE Study Collaborative Group. Safety and efficacy of longterm statin treatment for cardiovascular events in patients with coronary heart disease and abnormal liver tests in the Greek Atorvastatin and Coronary Heart Disease Evaluation (GREACE) Study: a post-hoc analysis. Lancet 2010; 376: 1916-22.

136. Athyros VG, Giouleme O, Ganotakis ES, et al. Safety and impact on cardiovascular events of long-term multifactorial treatment in patients with metabolic syndrome and abnormal liver function tests: a post hoc analysis of the randomised ATTEMPT study. Arch Med Sci 2011; 7: 796-805.

137. Katsiki N, Athyros VG, Karagiannis A, Mikhailidis DP. Smoking and non-alcoholic steatohepatitis (NASH): the GREek Atorvastatin and Coronary heart disease Evaluation (GREACE) trial. J Hepatol 2012; 57: 476.

138. Athyros VG, Tziomalos K, Daskalopoulos GN, Karagiannis A, Mikhailidis DP. Statin-based treatment for cardiovascular risk and non-alcoholic fatty liver disease. Killing two birds with one stone? Ann Med 2011; 43: 167-71.

139. Foster T, Budoff MJ, Saab S, Ahmadi N, Gordon C, Guerci AD. Atorvastatin and antioxidants for the treatment of nonalcoholic fatty liver disease: the St Francis Heart Study randomized clinical trial. Am J Gastroenterol 2011; 106: 71-7.

140. Tikkanen MJ, Fayyad R, Faergeman O, et al.; On behalf of the IDEAL Investigators. Effect of intensive lipid lowering with atorvastatin on cardiovascular outcomes in coronary heart disease patients with mild-to-moderate baseline elevations in alanine aminotransferase levels. Int J Cardiol 2013; 168: 3846-52.

141. Nikolic D, Banach M, Nikfar S, et al.; Lipid and Blood Pressure Meta-Analysis Collaboration Group. A meta-analysis of the role of statins on renal outcomes in patients with chronic kidney disease. Is the duration of therapy important? Int J Cardiol 2013; 168: 5437-47.

142. Lonardo A, Sookoian S, Chonchol M, Loria P, Targher G. Cardiovascular and systemic risk in nonalcoholic fatty liver disease - atherosclerosis as a major player in the natural course of NAFLD. Curr Pharm Des 2013; 19: 5177-92.

143. Abrass CK. Cellular lipid metabolism and the role of lipids in progressive renal disease. Am J Nephrol 2003; 24: 46-53.

144. Gluba A, Rysz J, Banach M. Statins in patients with chronic kidney disease: why, who and when? Expert Opin Pharmacother 2010; 11: 2665-74.
145. Rysz J, Aronow WS, Stolarek RS, Hannam S, Mikhailidis DP, Banach M. Nephroprotective and clinical potential of statins in dialyzed patients. Expert Opin Ther Targets 2009; 13: 541-50.

146. Shepherd J, Kastelein JJ, Bittner V, et al. Intensive lipid lowering with atorvastatin in patients with coronary heart disease and chronic kidney disease: the TNT (Treating to New Targets) study. J Am Coll Cardiol 2008; 51: 1448-54.

147. Weiner DE, Tighiouart H, Amin MG, et al. Chronic kidney disease as a risk factor for cardiovascular disease and all-cause mortality: a pooled analysis of community-based studies. J Am Soc Nephrol 2004; 15: 1307-15.

148. Barylski M, Nikfar S, Mikhailidis DP, et al.; Lipid and Blood Pressure Meta-Analysis Collaboration Group. Statins decrease all-cause mortality only in CKD patients not requiring dialysis therapy: a meta-analysis of 11 randomized controlled trials involving 21,295 participants. Pharmacol Res 2013; 72: 35-44.

149. Dormuth CR, Hemmelgarn BR, Paterson JM, et al. Use of high potency statins and rates of admission for acute kidney injury: multicenter, retrospective observational analysis of administrative databases. BMJ 2013; 346: f880.

150. Marenzi G, Cosentino N, Werba JP, Tedesco CC, Veglia F, Bartorelli AL. A meta-analysis of randomized controlled trials on statins for the prevention of contrast-induced acute kidney injury in patients with and without acute coronary syndromes. Int J Cardiol 2015; 183: 47-53.

151. Gluba A, Banach M, Hannam S, Mikhailidis DP, Sakowicz A, Rysz J. The role of Toll-like receptors in renal diseases. Nat Rev Nephrol 2010; 6: 224-35.

152. Rysz J, Banach M, Cialkowska-Rysz A, et al. Blood serum levels of IL-2, IL-6, IL-8, TNF-alpha and IL-1beta in patients on maintenance hemodialysis. Cell Mol Immunol 2006; 3: 151-4.

153. Tonelli M, Wanner C; Kidney Disease: Improving Global Outcomes Lipid Guideline Development Work Group Members. Lipid management in chronic kidney disease: synopsis of the kidney disease: improving global outcomes 2013 clinical practice guideline. Ann Intern Med 2014; 160: 182-9.

154. Frishman WH, Aronow WS, Cheng-Lai A. Cardiovascular drug therapy in the elderly. In: Aronow WS, Fleg J, Rich MW (eds.). Tresch and Aronow's cardiovascular disease in the elderly. Fifth edition, Boca Raton, London, New York, CRC press, 2013; 67-103.

155. Szadkowska I, Stanczyk A, Aronow WS, et al. Statin therapy in the elderly: a review. Arch Gerontol Geriatr 2010; 50: 114-8.

156. Novak LP. Aging, total body potassium, fat-free mass and cell mass in males and females between the ages of 18 and 85 years. J Gerontom 1972; 27: 438-43.

157. Schmucker DL. Aging and drug disposition: an update. Pharmacol Rev 1985; 37: 133-48.

158. Cheng JWM, Frishman WH, Aronow WS. Updates on cytochrome P450-mediated cardiovascular drug interactions. Am J Therap 2009; 16: 155-63.

159. Armitage J. The safety of statins in clinical practice. Lancet 2007; 370: 1781-90.

160. Thomas JE, Foody JM. Disorders of lipid metabolism. In: Aronow WS, Fleg JL, Rich MW (eds). Cardiovascular disease in the elderly. Fourth edition, New York, London, Informa Healthcare 2008; 159-78.

161. Heart Protection Study Collaborative Group. MRC/BHF Heart Protection Study of cholesterol lowering with 
M. Banach, M. Rizzo, P.P. Toth, M. Farnier, M.H. Davidson, K. Al-Rasadi, W.S. Aronow, V. Athyros, D.M. Djuric, M.V. Ezhov, R.S. Greenfield, G.K. Hovingh, K. Kostner, C. Serban, D. Lighezan, Z. Fras, P.M. Moriarty, P. Muntner, A. Goudev, R. Ceska, S.J. Nicholls, M. Broncel,

D. Nikolic, D. Pella, R. Puri, J. Rysz, N.D. Wong, L. Bajnok, S.R. Jones, K.K. Ray, D.P. Mikhailidis

simvastatin in 20,536 high-risk individuals: a randomised placebo-controlled trial. Lancet 2002; 360: 7-22.

162. Shepherd J, Blauw GJ, Murphy MB, et al. Pravastatin in elderly individuals at risk of vascular disease (PROSPER): a randomised controlled trial. Lancet 2002; 360: 1623-30

163. LaRosa JC, Grundy SM, Waters DD, et al. Intensive lipid lowering with atorvastatin in patients with stable coronary disease. N Eng J Med 2005; 352: 1425-35.

164. Roberts CGP, Guallar E, Rodriguez A. Efficacy and safety of statin monotherapy in older adults: a meta-analysis. J Gerontol Med Sci 2007; 62A: 879-87.

165. Martin SS, Blumenthal RS. Disorders of lipid metabolism. In: Aronow WS, Fleg J, Rich MW (eds). Tresch and Aronow's cardiovascular disease in the elderly. Fifth edition, Boca Raton, London, New York, CRC press, 2013; 121-42.

166. Sica DA, Gehr TW. Rhabdomyolysis and statin therapy: relevance to the elderly. Am J Geriatr Cardiol 2002; 11 48-55.

167. Rizzo M, Nikolic D, Banach M, Montalto G. Statin treatment in the elderly: how much do we know? Arch Med Sci 2013; 9: 585-8.

168. McCarey DW, McInnes IB, Madhok R, et al. Trial of Atorvastatin in Rheumatoid Arthritis (TARA): doubleblind, randomised placebo-controlled trial. Lancet 2004; 363: 2015-21.

169. Mihos CG, Artola RT, Santana O. The pleiotropic effects of the hydroxy-methyl-glutaryl-CoA reductase inhibitors in rheumatologic disorders: a comprehensive review. Rheumatol Int 2012; 32: 287-94.

170. Buettner C, Rippberger MJ, Smith JK, Leveille SG, Davis RB, Mittleman MA. Statin use and musculoskeletal pain among adults with and without arthritis. Am J Med 2012; 125: 176-82.

171. Noel B. Lupus erythematosus and other autoimmune diseases related to statin therapy: a systematic review. J Eur Acad Dermatol Venereol 2007; 21: 17-24.

172. del Rincón ID, Williams K, Stern MP, et al. High incidence of cardiovascular events in rheumatoid arthritis cohort not explained by traditional risk factors. Arthritis Rheum 2001; 44: 2737-45.

173. De Vera MA, Choi H, Abrahamowicz M, Kopec J, Lacaille $\mathrm{D}$. Impact of statin discontinuation on mortality in patients with rheumatoid arthritis: a population-based study. Arthritis Care Res (Hoboken) 2012; 64: 809-16.

174. Liakopoulos OJ, Choi YH, Haldenwang PL, et al. Impact of preoperative statin therapy on adverse postoperative out-comes in patients undergoing cardiac surgery: a meta-analysis of over 30,000 patients. Eur Heart J 2008; 29: 1548-59.

175. Molnar AO, Coca SG, Devereaux PJ, et al. Statin use as sociates with a lower incidence of acute kidney injury after major elective surgery. J Am Soc Nephrol 2011 22: 939-46.

176. Iannuzzi JC, Rickles AS, Kelly KN, et al. Perioperative pleiotropic statin effects in general surgery. Surgery 2014; 155: 398-407.

177. Lindenauer PK, Pekow P, Wang K, Gutierrez B, Benjamin EM. Lipid lowering therapy and in-hospital mortality following major noncardiac surgery. JAMA 2004; 291: 2092-9.

178. Hindler K, Shaw AD, Samuels J, Fulton S, Collard CD, Riedel B. Improved postoperative outcomes associated with preoperative statin therapy. Anesthesiology 2006; 105: 1260-72.
179. Poldermans D, Bax JJ, Boersma E, et al. Guidelines for pre-operative cardiac risk assessment and perioperative cardiac management in non-cardiac surgery. Eur Heart J 2009; 30: 2769-812.

180. Le Manach Y, Godet G, Coriat P, et al. The impact of post-operative discontinuation or continuation of chronic statin therapy on cardiac outcome after major vascular surgery. Anesth Analg 2007; 104: 1326-33.

181. Kristensen SD, Knuuti J, Saraste A, et al.; Authors/Task Force Members. 2014 ESC/ESA Guidelines on non-cardiac surgery: cardiovascular assessment and management: The Joint Task Force on non-cardiac surgery: cardiovascular assessment and management of the European Society of Cardiology (ESC) and the European Society of Anaesthesiology (ESA). Eur Heart J 2014 35: 2383-431.

182. Degreef LE, Opdam FL, Teepe-Twiss IM, Jukema JW, Guchelaar HJ, Tamsma JT. The tolerability and efficacy of low-dose simvastatin in statin-intolerant patients. Eur J Intern Med 2010; 21: 293-6.

183. Glueck CJ, Abuchaibe C, Wang P. Symptomatic myositis-myalgia in hypercholesterolemic statin-treated patients with concurrent vitamin D deficiency leading to statin intolerance may reflect a reversible interaction between vitamin $D$ deficiency and statins on skeletal muscle. Med Hypotheses 2011; 77: 658-61.

184. Sullivan D, Olsson AG, Scott R, et al. Effect of a monoclonal antibody to PCSK9 on low-density lipoprotein cholesterol levels in statin-intolerant patients: the GAUSS randomized trial. JAMA 2012; 308: 2497-506.

185. Banach M, Aronow WS, Serban C, et al. Lipids, blood pressure and kidney update 2014. Pharmacol Res 2015; in press.

186. Stroes E, Colquhoun D, Sullivan D, et al. Anti-PCSK9 antibody effectively lowers cholesterol in patients with statin intolerance: the GAUSS-2 randomized, placebo-controlled phase 3 clinical trial of evolocumab. J Am Coll Cardiol 2014; 63: 2541-8.

187. Goal Achievement After Utilizing an Anti-PCSK9 Antibody in Statin Intolerant Subjects-3 (GAUSS-3). ClinicalTrials.gov Identifier: NCT01984424.

188. Dragan S, Serban MC, Banach M. Proprotein convertase subtilisin/kexin 9 inhibitors: an emerging lipid-lowering therapy? J Cardiovasc Pharmacol Ther 2015; 20: 157-68

189. Moriarty PM, Jacobson TA, Bruckert E, et al. Efficacy and safety of alirocumab, a monoclonal antibody to PCSK9, in statin-intolerant patients: design and rationale of ODYSSEY ALTERNATIVE, a randomized phase 3 trial. J Clin Lipidol 2014; 8: 554-61.

190. Guyton JR, Bays HE, Grundy SM, Jacobson TA; The Na tional Lipid Association Statin Intolerance Panel. An assessment by the Statin Intolerance Panel: 2014 update. J Clin Lipidol 2014; 8 (3 Suppl): S72-81.

191. Visser ME, Wagener G, Baker BF, et al. Mipomersen, an apolipoprotein B synthesis inhibitor, lowers low-density lipoprotein cholesterol in high-risk statin-intolerant patients: a randomized, double-blind, placebo-controlled trial. Eur Heart J 2012; 33: 1142-9.

192. Donnelly LA, Doney AS, Tavendale R, et al. Common nonsynonymous substitutions in SLCO1B1 predispose to statin intolerance in routinely treated individuals with type 2 diabetes: a go-DARTS study. Clin Pharmacol Ther 2011; 89: 210-6.

193. Raju SB, Varghese K, Madhu K. Management of statin intolerance. Indian J Endocrinol Metab 2013; 17 977-82. 
194. Finegold JA, Manisty CH, Goldacre B, Barron AJ, Francis DP. What proportion of symptomatic side effects in patients taking statins are genuinely caused by the drug? Systematic review of randomized placebo-controlled trials to aid individual patient choice. Eur J Prevent Cardiol 2014; 21: 464-74.

195. Abd TT, Jacobson TA. Statin-induced myopathy: a review and update. Expert Opin Drug Saf 2011; 10: 373-87.

196. Law M, Rudnicka AR. Statin safety: a systematic review. Am J Cardiol 2006; 97: 52C-60C.

197. Needham M, Mastaglia FL. Statin myotoxicity: a review of genetic susceptibility factors. Neuromuscul Disord 2014; 24: 4-15.

198. Bays H, Cohen DE, Chalasani N, Harrison SA. The National Lipid Association's Statin Safety Task Force. An assessment by the Statin Liver Safety Task Force: 2014 update. J Clin Lipidol 2014; 8 (3 Suppl): S47-57.

199. Wei MY, Ito MK, Cohen JD, Brinton EA, Jacobson TA. Predictors of statin adherence, switching, and discontinuation in the USAGE survey: understanding the use of statins in America and gaps in patient education. J Clin Lipidol 2013; 7: 472-83.

200. Sathasivam S, Lecky B. Statin induced myopathy. BMJ 2008; 337: a2286.

201. Phillips PS, Haas RH, Bannykh S, et al. Statin-associated myopathy with normal creatine kinase levels. Ann Intern Med 2002; 137: 581-5.

202. Abukres SH, Hoti K, Hughes JD. Patient attitudes towards a new role for pharmacists: continued dispensing. Patient Prefer Adherence 2014; 8: 1143-51. 